Rhode Island College

Digital Commons @ RIC

$5-1-2013$

\title{
Improving Nurse Satisfaction and Knowledge of Therapeutic Hypothermia Using a Staff Education Program and Evidence- Based Protocol
}

Laura Anne Cresap Goldstein

Rhode Island College

Follow this and additional works at: https://digitalcommons.ric.edu/etd

Part of the Nursing Commons

\section{Recommended Citation}

Goldstein, Laura Anne Cresap, "Improving Nurse Satisfaction and Knowledge of Therapeutic Hypothermia Using a Staff Education Program and Evidence-Based Protocol" (2013). Master's Theses, Dissertations, Graduate Research and Major Papers Overview. 218.

https://digitalcommons.ric.edu/etd/218

This Major Paper is brought to you for free and open access by the Master's Theses, Dissertations, Graduate Research and Major Papers at Digital Commons @ RIC. It has been accepted for inclusion in Master's Theses, Dissertations, Graduate Research and Major Papers Overview by an authorized administrator of Digital Commons @ RIC. For more information, please contact digitalcommons@ric.edu. 


\section{IMPROVING NURSE SATISFACTION AND KNOWLEDGE}

OF THERAPEUTIC HYPOTHERMIA USING A STAFF EDUCATION

PROGRAM AND EVIDENCE-BASED PROTOCOL

by

Laura Anne Cresap Goldstein

A Major Paper Submitted in Partial Fulfillment

of the Requirements for the Degree of

Master of Science in Nursing

in

The School of Nursing

Rhode Island College

2012 


\title{
IMPROVING NURSE SATISFACTION AND KNOWLEDGE OF THERAPEUTIC HYPOTHERMIA USING A STAFF EDUCATION PROGRAM AND EVIDENCE-BASED PROTOCOL
}

\author{
A Major Paper Presented
}

By

Laura Anne Cresap Goldstein

Approved:

Committee Chairperson

Committee Members

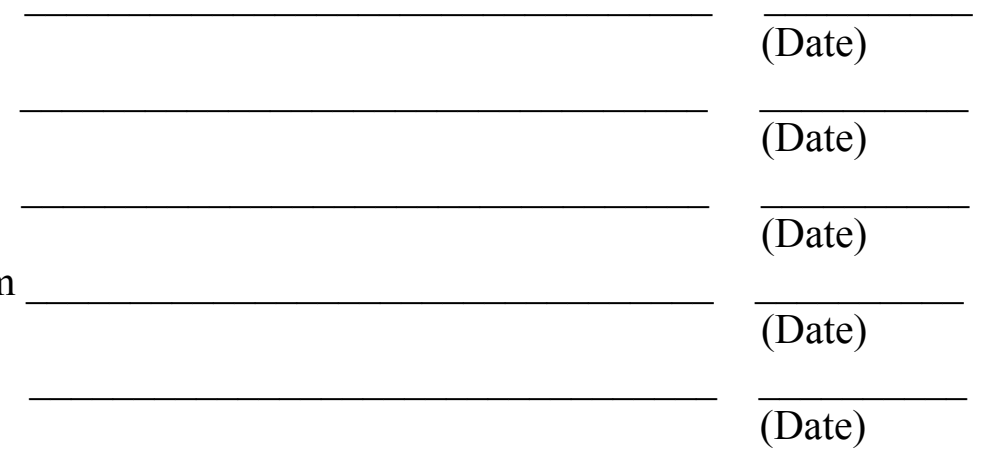

Director of Master's Program

Dean, School of Nursing

(Date) 


\begin{abstract}
Mild Therapeutic Hypothermia (TH) or Targeted Temperature Management (Nunnally et al., $2011)$ is defined as an intentional reduction of a patient's core temperature to $32^{\circ} \mathrm{C}-34^{\circ} \mathrm{C}(89.6$ 93. $2^{\circ} \mathrm{F}$ ) following ventricular fibrillation (V-Fib) sudden cardiac arrest (SCA) with return of spontaneous circula-tion (ROSC), and who remain unconscious, for the purposes of limiting neurologic reperfusion injury (Polderman, \& Herold, 2009). Mild TH is a highly valuable post cardiac arrest procedure that can result in preservation of neurologic function and reduction of the inflammatory effects of neurologic reperfusion syndrome following cardiac arrest. This procedure requires specific educational preparation in order to perform the procedure and anticipate the potential complications that might occur during nursing care. TH involves the use of specialized equipment, systematic education, and a team approach to be effective.

Educational needs should be addressed in a variety of presentations over time to provide staff with the knowledge and confidence to care for these patients. The purpose of this project was to develop an educational program for critical care and emergency department nurses caring for patients undergoing TH. Development was guided by review of the literature, theoretical framework, assessment of need, and reevaluation of learning. This program development project highlights the role of the CNS in identifying, teaching, and evaluating learning for nurses in the Intensive Care Unit and Emergency Department.
\end{abstract}




\section{Acknowledgements}

I want to thank Dr. Cynthia Padula for her advice and support as my professor, mentor and first reader. I want to thank Dr. Nancy Blasdell for her help as my second reader. I want to thank Kathy Bergeron, RN, MS, APRN as my teacher, friend, and third reader for her help and support throughout this project. I would also like to thank my children Keith and Rachel for their love and support of my education. 


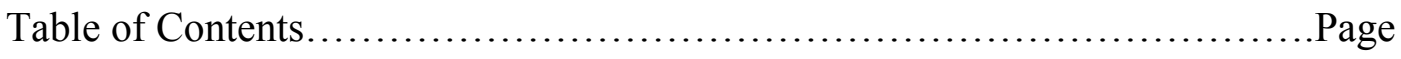

Statement of the Problem....................................................... 1

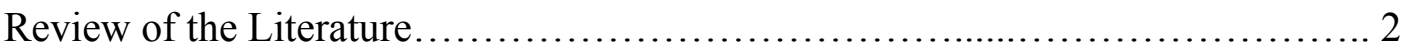

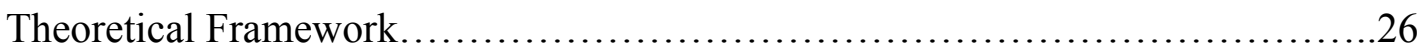

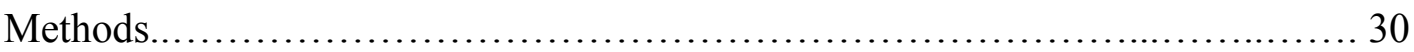

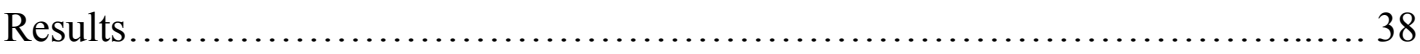

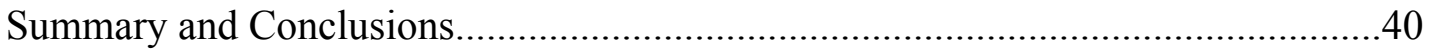

Implications for Advanced Nursing Practice.............................................42

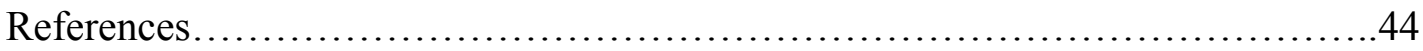

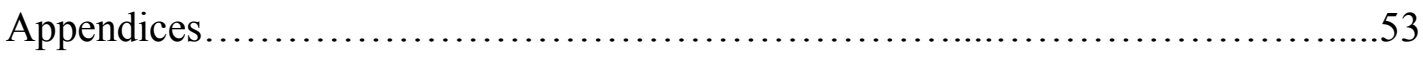


Improving Nurse Satisfaction and Knowledge of Therapeutic Hypothermia Using A Staff Education Program and Evidence-Based Protocol

\section{Statement of the Problem}

Mild Therapeutic Hypothermia (TH), or targeted temperature management (Nunnally et al., 2011), is defined as an intentional reduction of a patient's core temperature to $32^{\circ} \mathrm{C}-34^{\circ} \mathrm{C}(89.6$ $-93.2^{\circ} \mathrm{F}$ ) following ventricular fibrillation (V-Fib) sudden cardiac arrest (SCA) with return of spontaneous circulation (ROSC), and who remains unconscious, for the purposes of limiting neurologic reperfusion injury (Polderman \& Herold, 2009). For the purpose of this paper, the term mild TH will be used as defined above. Mild TH is a highly valuable post cardiac arrest procedure that can result in preservation of neurologic function and reduction of the inflamematory effects of neurologic reperfusion syndrome following cardiac arrest. Implementing this procedure requires specific educational preparation in order for nurses to perform the procedure and anticipate the potential complications that might occur during nursing care. The purpose of this project was to develop an educational program for critical care and emergency department nurses caring for patients undergoing $\mathrm{TH}$. 


\section{Review of the Literature}

A comprehensive literature search was done using PubMed and key words including: sudden cardiac death; cardiac resuscitation; history of hypothermia; hypothermia equipment; therapeutic hypothermia and post cardiac arrest care. Literature was searched from 1900 to present. The reference list from each article was reviewed and author and subject were searched in Google Scholar.

\section{Background/Statistics}

Cardiovascular disease is a leading cause of death worldwide. Survival from cardiac arrest (SCA) outside or in hospital with no neurologic damage is a desirable outcome. However, medical statistics of survival are discouraging. SCA from V-fib is a leading cause of death in the US, accounting for an estimated 350,000 deaths a year (Heart Rhythm Foundation, 2002). Ninetyfive percent of victims die before reaching the hospital or emergency help (American Heart Association [AHA], 2009). Forty percent of those undergoing resuscitation for cardiac arrest will have a return of spontaneous circulation (ROSC) (Koran, 2009). The rates of survival to dis-charge after in-hospital cardiac arrest are $27 \%$ in children and $17 \%$ in adults, and $30 \%$ of SCA survivors (Koran) will have severe brain damage (AHA, 2009).

\section{Historical Perspective: Therapeutic Hypothermia (TH)}

TH has been intensely studied as a means of improving survival. The use of hypothermia in modern clinical medicine is documented in medical literature dating back 200 years (Varon $\&$ Acosta, 2008). In 1803, Russians attempted to use hypothermia therapeutically when they covered patients with snow in an attempt to resuscitate them (Karpovich, 1953; Liss, 1986). In 1812, Baron de Larrey cooled injured limbs to numb the pain prior to amputation (Mordecai, Globus \& Dietrich, 1992). Over a hundred years later, in 1937, Dr. Temple Fay cooled a cancer 
patient to $32{ }^{\circ} \mathrm{C}$ in an attempt to prevent cancer cells from multiplying (Fay, 1940), and Smith \& Fay (Smith \& Fay, 1940) later reported on the effects that induced hypothermia caused in cancer patients (1940). Bigelow and McBirnie (Bigelow \& McBirnie, 1953) published a study that used dog and monkey models in cardiac surgery, and noted the beneficial effects of TH on the brain and heart (1953). Rosomoff and Holaday (Rosomoff \& Holaday, 1954) demonstrated a direct effect between body temperature, intercranial pressure and brain volume. These early investigators confirmed that $\mathrm{TH}$ reduced cerebral oxygen consumption blood flow and metabolic rate in a normal dog brain. By 1959, induced TH was widely used by neurosurgeons for head and spinal cord injuries and in cardiac surgery.

Outside the operating room, TH had many indications as well. Benson and colleagues reported a case series of cardiac arrest patients who had positive outcomes following $\mathrm{TH}$ (Benson, Williams \& Spencer,1959). However, a number of complications were observed, including cardiac irritability, V-fib with deep hypothermia (body temperature $<30^{\circ} \mathrm{C}$ ), and a decreased clearance rate of staphylococcal bacteremia. These complications made the use of TH risky, and as a result, it was mostly abandoned between 1960 and the late 1990's (Varon \& Acosta, 2008).

While clinical applications of TH were limited in the years between 1950 and 1990, laboratory research continued. One of the primary TH researchers, Dr. Peter Safar studied the effects of mild hypothermic cardiopulmonary resuscitation in dogs during the 1990's. A highly respected researcher, Dr. Safar was credited with the invention of the modern cardiopulmonary resuscitation (CPR). Trained in anesthesiology, he founded the first critical care unit in the United States in 1958 and the world's first critical care medicine program at the University of Pittsburgh in 1961. He was a founding member of the American Heart Association Committee 
on CPR in 1963. He founded the Society of Critical Care Medicine in 1970 and the International Resuscitation Research Center at the University of Pittsburgh in 1979. A prolific writer, he published 384 peer-reviewed publications, more than thirty books and more than 600 abstracts on respiratory therapy, public health considerations in critical care medicine, anesthesiology, CPR, and emergency medicine during his lifetime (Acierno \& Worrell, 2007)

In 1988, Dr. Safar published a review article in Critical Care Medicine (Safar, 1988) in which he reviewed pathophysiologic limits and therapeutic potentials of resuscitation including TH. He reviewed the state of the art resuscitation science, discussed post resuscitation syndrome and reviewed potential treatments including TH. He cited an ongoing controlled animal outcome study of post cardiac arrest hypothermia and concluded that the treatment should be pursued further. He suggested further research studies on TH timing, levels, methods of administration, and prospective outcome evaluations be done.

In 1996, Dr. Safar and colleagues (Safar et al., 1996) published a study of a multifaceted combination treatment following cardiac arrest utilizing a dog model. The study utilized 16 dogs. The dogs were divided into two groups, exposed to normothermia and mild hypothermia following induced ventricular fibrillation for 11 minutes. The study dogs were given controlled reprofusion, defibrillation, and controlled ventilation for up to 20 hours. The control group was kept normotensive, normothermic, and hypocapnic. The experimental group received mild resuscitative hypothermia for 10 minutes to 12 hours plus cerebral blood flow promotion with induced moderate hypertension, mild hemo-dilution and normocapnea. He concluded that while all 16 dogs survived, at 96 hours the control group (eight dogs) treated with normothermia had overall neurologic performance score of 3 (severe disability) or 4 (coma). Of the dogs in the experimental mild hypothermia group, six dogs achieved a neurologic performance score of 1 
(normal), one dog had a performance score of 2 (moderate disability), and 1 dog had a score of 3 (severe disability). He concluded that resuscitative mild hypothermia plus cerebral blood flow promotion can achieve functional recovery with the least histological brain damage.

\section{Landmark Prospective Randomized Studies}

Support for $\mathrm{TH}$ was also limited because there were no prospective randomized trials to support the theories. In 2002, the results of two landmark prospective randomized trials were published in the February issue of The New England Journal of Medicine. In the first study, conducted in Australia at four hospitals, Bernard and colleagues (Bernard et al., 2002) studied the treatment of comatose survivors of out-of-hospital cardiac arrest with induced hypothermia. The study involved 77 subjects randomly assigned to treatment with TH or normothermia. The primary outcome measure was survival to hospital discharge with sufficiently good neurologic function to be discharged to home or to a rehabilitation facility. In the study, 21 of 43 (48\%) subjects treated with TH survived to discharge with good neurologic function. In contrast, only nine subjects $(26 \%)$ out of 34 who were treated with normothermia survived to discharge with good neurologic outcomes. Treatment with moderate $\left(33^{\circ} \mathrm{C}\right) \mathrm{TH}$ appeared to improve neurologic outcomes in patients in coma after resuscitation from out-of-hospital cardiac arrest.

The second study was the HACA Group Trial (Hypothermia after Cardiac Arrest Study Group, 2002) and it involved nine centers in five European countries. This multicenter study enrolled subjects who had been resuscitated after cardiac arrest from V-fib. Participants were randomly assigned to undergo $\mathrm{TH}$ over a period of 24 hours or to receive standard therapy and normothermia. The primary endpoint was a favorable neurologic outcome within six months after cardiac arrest. A total of 136 subjects underwent $\mathrm{TH}$ while 137 subjects were treated with normothermia. Of the TH group, 75 out of $136(56 \%)$ subjects had a favorable outcome as com- 
pared to 54 out of 137 (39\%) who were not subjected to TH. In this study, mild TH was shown to improve the neurologic outcome after cardiac arrest. The investigators concluded that the use of $\mathrm{TH}$ in cases of successful resuscitation from cardiac arrest due to V-Fib increased the rate of a favorable neurologic outcome and reduced overall mortality.

These two trials showed the usefulness of TH. While similar, each study had differences in hypothermia technique and each study had a protocol but used different cooling techniques. The HACA study cooled subjects with an external cooling device to maintain body temperature, while the Bernard study subjects were cooled with ice packs applied to the patient. The two studies identified potential complications including hypoglycemia, bleeding, thrombocytopenia, pneumonia, sepsis, pancreatitis, renal failure, lethal or long-lasting arrhythmias, pulmonary edema, seizures, and skin breakdown.

\section{Determining the Number of Patients Needed to Treat to Save One}

In a meta-analysis by Holtzer and colleagues (Holtzer et al., 2005), the reviewers concluded that mild TH improved short-term neurologic recovery and survival in patients resuscitated from cardiac arrest of presumed cardiac origin. Holtzer et al. reviewed randomized and quasirandomized, controlled trials of adults successfully resuscitated where TH was applied within six hours after arrival to the emergency department and neurologic outcomes were compared. Three randomized trials were identified, and the analyses were conducted according to the intention-to-treat principle. One study followed patients to six months or death. Those patients who were alive at six months with favorable functional neurologic recovery were more likely to be in the hypothermia treatment group (risk ratio, 1.44 ; 95\% confidence level, 1.11 1.76). Summary odds were calculated for the three trials using a random effects model and translated into risk ratios. More patients in the hypothermia group were discharged with 
favorable neurologic recovery (risk ratio, $1.29-2.07$ ). The $95 \%$ confidence interval of the number of $\mathrm{TH}$ patients needed to treat to allow one additional $\mathrm{TH}$ patient to leave the hospital was between 4-13 patents. The reviewers concluded that "This compares well with many pharmacologic interventions in patients with acute cardiovascular diseases” (p. 417).

\section{Percutaneous Coronary Intervention and TH Studies}

Since 2004, The American College of Cardiology (ACC) and the AHA for the Management of Patients with ST-Elevation Myocardial Infarction (Antman et al., 2004) has recommended the use of Percutaneous Coronary Intervention (PCI). Hovdenes and colleagues (Hovdenes, Lakke, Aberge, Haugaa, \& Bugge, 2007) reported on a retrospective study done in a tertiary hospital in Norway that utilized treatment with both TH and PCI.

The study was done to examine results of a newly adopted change in practice in the ED and ICU. The study followed treatment outcomes and follow-up of 50 consecutive subjects admitted to the hospital after out-of-hospital cardiac arrest (OOHCA) caused by VFib and treated with PCI and angioplasty. The study hospital had a TH protocol that included PCI and patients were often cooled in transport to the hospital. Patients were brought directly to the cardiac catheterization laboratory for immediate coronary angiography and primary or facilitated PCI. Subjects who had PCI were given medications to inhibit clotting including aspirin, clopidogrel (Plavix) and abciximab (Reopro) under the hospital's PCI protocol. Despite the effect of the medications, no serious bleeding was observed in patients. Patients who were hemodynamically unstable were put on an intra-aortic balloon pump (IABP) and most patients were monitored invasively with a pulmonary artery catheter.

Primary endpoints of the study were defined as survival and neurologic outcome after six months. Forty-one patients (82\%) survived to six months. Neurologic performance was 
assessed by use of the Pittsburgh Cerebral Performance Categories (CPC) of 1 to 5. CPC 1 is defined as a return to normal cerebral functioning, while CPC 5 is defined as death. Thirty-four patients $(68 \%)$ were in CPC 1 or 2 , while seven patients $(14 \%)$ were rated at CPC 3 . Of the 23 patients treated with IABP, 14 (61\%) survived with a CPC 1 or 2 . In patients not treated with IABP, 20 patients (74\%) survived with a CPC of 1 or 2 , and 40 patients (80\%) developed myocardial infarction. PCI was performed on 36 patients (72\%). The researchers concluded that in the OOHCA survivors who reached the hospital, the survival rate was high and the neurological outcome was acceptable. They concluded that the use of TH was justified even in hemodynamically unstable patients. They also demonstrated that hemodynamically unstable post cardiac arrest patients eligible for TH may benefit from PCI.

Several research studies published in 2007 and 2008 supported Hovdenes’ (2007) use of PCI as part of a standardized treatment protocol for post resuscitation care after OOHCA. In a prospective observational study in Oslo Norway over 20.5 months, Sunde and colleagues (2007) studied 61 patients with OOHCA and PCI versus 58 control patients from the previous 24 months. The percentage of patients with acute MI was the same in both groups. Fifty-two patients in each group were comatose on admission. Thirty-three $(57 \%)$ of the control patients were diagnosed with MI. Thirty-six patients in the interventional group (59\%) were diagnosed with MI. Forty-seven (77\%) patients in the intervention group underwent coronary angiography and 30 patients (49\%) had a PCI. Of the control group, two patients $(3 \%)$ received thrombolytic treatment. Forty patients in the interventional group underwent TH. None of the control group had TH.

The primary outcome of the study was survival to hospital discharge with a favorable neurologic outcome defined as a CPC of 1 (good recovery) or 2 (moderate disability). The 
secondary outcome was survival at one year. Fifteen (26\%) of 58 control group patients survived to hospital discharge. Thirty-four (56\%) of 61 patients survived to discharge of the interventional group. All survivors with a favorable neurologic outcome in both groups were still alive at one year.

In another study, Wolfrum and colleagues (Wolfrum, Pierau, Radke, Schunkert \& Kurowski, 2008) conducted a single center observational study at a university clinic with 33 patients OOHCA and ROSC who remained comatose on admission and presented with acute ST segment elevation MI (STEMI). TH was started in 16 of the patients immediately after admission and continued during PCI. Seventeen patients in the control group from a similar observational study were given PCI without the TH protocol. At six months, the patients treated with PCI and TH had a survival rate of $75 \%$ compared with the control group survival rate of $65 \%$. The researchers recommended that $\mathrm{TH}$ in combination with PCI should be strongly considered as standard therapy in patients with OOHCA due to STEMI.

\section{Development of TH Equipment}

As interest in TH grew, so did research into the best way to cool patients. The cooling process was nursing labor intensive, requiring 1:1 staffing. The rate of cooling and maintaining the patient at the desired temperature was difficult to control. If the patient was cooled below 32 $32{ }^{\circ} \mathrm{C}$, lethal arrhythmias could occur. No specific guidelines for cooling equipment were available for noninvasive induction of hypothermia at the time of the two landmark studies. The HACA study (2002) cooled subjects with an external cooling device (cooling blanket) to maintain body temperature, while in the Bernard study (2002) subjects were cooled with ice packs applied to the patient. Noninvasive methods included ice packs, fans, alcohol baths and cooling blankets. 
Several studies examined the use and efficacy of new hpothermia equipment. HachimiIdrissi et al. (2001) described the use of a device containing a solution of aqueous glycerol around the head and neck to cool the patient to $34{ }^{\circ} \mathrm{C}$. Patients who had cardiac arrest from pulseless electric activity or asystole of presumed cardiac origin were considered for the trial. Thirty patients were enrolled, with 16 patients in the hypothermia group and 14 in the normothermic group. Lactate concentration and oxygen extraction ratios were significantly lower at the end of the study in the hypothermia group. The researchers concluded that mild hypothermia induced by a helmet device was feasible, easy to perform, inexpensive, and effective with no increase in complications.

Georgiadis and colleagues (2001) were the first to study an endovascular catheter with moderate hypothermia in patients with acute stroke. In a study involving six patients with severe acute ischemic stroke, participants were intubated and sedated. Participants were treated with moderate hypothermia induced by a specially designed closed loop central line catheter inserted in the femoral vein and advanced to the inferior vena cava. Temperature adjusted normal saline was circulated in a closed loop system entailing three balloons located near the tip of the central line catheter. The pace of cooling was $1.4{ }^{\circ} \mathrm{C} / \mathrm{hr}$ with a variation of $0.6^{\circ} \mathrm{C}$. During hypothermia, the maximal temperature was reached in 3 (range 2 to 4.5 hours) hours. Maximal temperature observed was $33.4{ }^{\circ} \mathrm{C}$ and minimal temperature was $32.2^{\circ} \mathrm{C}$. Singulitis was the only device related complication noted. Pulmonary infection, arterial hypotension, bradycardia, arrhythmia, and thrombocytopenia were the most common side effects. Five of the six patients survived the acute phase of stroke. One patient died 59 hours after initiation of hypothermia because of uncontrollable intracranial hypertension. The authors concluded that induction and maintenance of hypothermia with an intravenous cooling device were safe and feasible. 
Al-Senani and colleagues (2004) conducted a prospective multi-center pilot study to evaluate the feasibility and safety of using the endovascular CoolGard System and Icy Catheters following cardiac arrest. The researchers studied 13 comatose patients successfully resuscitated after cardiac arrest. Core temperature was reduced to a target temperature of $33{ }^{\circ} \mathrm{C}$ for 24 hours followed by controlled rewarming. Time from cardiac arrest to ROSC was an average of 14.3 minutes. It took an average of 3 hours 39 minutes (median 210 minutes) to reach a target temperature of $33{ }^{\circ} \mathrm{C}$. Patients were maintained on hypothermia for 24 hours at an average of $32.7^{\circ} \mathrm{C}$ (range of $+/-0.5^{\circ} \mathrm{C}$ ). Controlled rewarming occured over an average of 18 hours; the average was 5.9 hours. Primary outcomes were speed and accuracy of cooling, survival to discharge, 30 day mortality, and the Glasgow Outcome Scale (Jennett \& Bond, 1975). The researchers used two neurologic scales: the Glasgow Out-come Scale (GOS) that employs scores ranging from 1-5, and the Glasgow Coma Scale (GCS) (Teasdale \& Jennett, 1974) with scores ranging from 3-15. Four patients died by the 30 day follow-up, however none from TH. These patients were given a GOS 5 score (brain death). Two patients were in a persistent vegetative state (GOS 4). Two patients were severely disabled (GOS 3). Five patients (38.5\%) had a 30 day GOS of 1-2 and experienced good neurologic recovery. The Glasgow Coma Scale (GCS) scores averaged 3.7 at baseline, indicating a comatose, unresponsive state. Patients showed an average GCS of $9.0(+/-4.9)$ by the end of the study period, showing significant improvement of neurologic function from a comatose state (as a matter of reference, a normal GCS score is 15, indicating an awake, mobile, verbally responsive individual). Cooling time, maintenance, and rewarming temperatures were tightly maintained. No unanticipated or procedure-related adverse events occurred. This single arm study concluded that in comatose survivors of cardiac arrest, hypothermia via endovascular methods is safe and feasible with target temperatures 
rapidly and precisely achieved and controlled.

Haugk and colleagues (2007) studied a new noninvasive surface cooling device for use in post-resuscitation in critical care. The researchers studied a convenience sample of 28 patients using a non-invasive surface cooling device called Artic Sun. They found that cooling, maintenance and re-warming times were within satisfactory limits for $\mathrm{TH}$ and concluded that the Artic Sun system was highly effective in lowering patient's temperature without inducing skin irritation.

Hoedemakers, Ezzahti, Gerritsen, and Van der Hoven (2007) conducted a prospective intervention study of different cooling methods to induce and maintain normothermia and hypothermia in ICU patients. Fifty adult ICU patients with indications for mild hypothermia were enrolled prospectively. Ten patients in each group were assigned in consecutive order to conventional cooling, cooling with water circulating blankets, air circulating blankets, water circulating gel coated pads, or an intravascular heat exchange system. The authors concluded that cooling with water circulating blankets, gel pads, and intravascular cooling were more efficient than conventional cooling with ice packs or air circulating blankets. The intravascular cooling system was shown to be the most reliable in maintaining a stable temperature.

However, all were shown to be effective in cooling, maintaining and rewarming patients in TH.

Medical device companies such as Stryker (Gaymar Medi-Therm Hyper/Hypothermia System), Cincinnati Sub-Zero Medical (Blanketrol III Body Temperature Regulation System), Medivance (Artic Sun System) have all developed extracorporeal devices for cooling. One company, Zoll Medical Corporation, developed intravascular cooling systems (Icy Catheter, Cool Line Catheter, Solex Catheter, Quattro Catheter) and CoolGard 3000 and Thermogard XP Systems. Automated external or internal cooling systems offer precise temperature regulation 
compared to the application of ice packs and IV cooled saline. The cost of TH equipment varies from inexpensive water blankets and body wraps such as those made by Gaymar and Blanketroll with machines costing approximately $\$ 10,000$ to systems using intravascular catheters costing upwards of $\$ 30,000$ each (Boehm, n.d.). The choice of equipment and cost is subject to hospital budgets and negotiation with suppliers.

\section{Assessing TH Cost Effectiveness}

While the safety and effectiveness of TH has been proven, many physicians and hospital administrators continued to debate the cost-effectiveness of the procedure. Would the investment of equipment and supplies as well as the training of staff justify the cost? How did the cost of the treatment compare with other interventions? How many patients needed to be treated to save one? Several articles have examined the process for determining cost effectiveness of TH and the implications for clinicians, hospital administrators, and other decision makers responsible for making informed choices about health care resource utilization.

Kirkland, Parham, and Pastores (2009) discussed the process by which intensivists might approach hospital administrators about adopting cooling technologies. Intensivists must play many roles as directors of intensive care units. They act as unit directors, clinicians, and marketing experts. As advocates of new technology, they need to assess the cost of equipment, staff training protocol development as well as implementation and assessment of patient care new to the ICU. Clinical Nurse Specialists may assist in this process. The intensivist must convince hospital administrators to invest in in expensive new technology and required staff training. The authors discussed the assessment and justification of cooling technology, vendor and product selection, economic analysis, and design thinking needed to make an informed choice. 
The cost to treat of an intervention is important because it addresses the utilization of resources required to perform the treatment. Merchant and colleagues (Merchant, Becker, Abella, Asch \& Groenveld, 2009) examined the cost effectiveness of TH after cardiac arrest. They post-ulated that when the cost to treat is high, the treatment may not be implemented if it consumes

an inordinate amount of resources. The researchers developed a decision model to capture costs and outcomes for patients with witnessed out-of-hospital VFib arrest who received conventional care or TH. They utilized the HACA trial inclusion criteria. Model inputs were determined from published data, cooling device companies, and consultation with resuscitation experts. Sensitivity analyses and Monte Carlo simulations were performed to identify influential variables and uncertainty in cost-effectiveness estimates. The main outcome measures were quality-adjusted survival after cardiac arrest, cost of hypothermia implementation, cost of posthospital discharge care, and incremental cost effectiveness ratios.

The researchers determined that post cardiac arrest patients receiving TH gained an average of 0.66 quality adjusted life years compared with conventional care, at a cost of $\$ 31,254$. This yielded an incremental cost effectiveness ratio of $\$ 47,168$ per quality-adjusted life year. Sensitivity analyses demonstrated that poor neurological outcome post cooling and costs associated with post hypothermia care, both in-hospital and long term, were the most influential variables in the model.

Even at extreme estimates for costs, the cost effectiveness of TH remained less than $\$ 100,000$ per quality-adjusted life year. In $91 \%$ of 10,000 Monte Carlo simulations, the incremental cost effectiveness ratio was less than $\$ 100,000$ per quality-adjusted life year. The re-searchers concluded that "even if only one patient per hospital per year was eligible for TH 
and considerable post-resuscitation care costs were accrued by survivors... the cost effectiveness of TH would remain less than $\$ 100,000$ per quality-adjusted life year" (p. 426). They also noted that "in cardiac arrest survivors who meet the HACA criteria, TH with a cooling blanket improves clinical outcomes with cost-effectiveness that is comparable to many economically acceptable health care interventions in the United States" (p. 421).

\section{Support for Therapeutic Hypothermia as a Standard of Care}

The AHA and the European Resuscitation Council reviewed the evidence in support of TH in 2002. The AHA, followed by the European Resuscitation Council (2003), recommended TH as a treatment method for out-of-hospital comatose victims of cardiac arrest. In 2007, the European Resuscitation Council on Hypothermia after Cardiac Arrest Registry Study Group (Arrich, 2007) published a study of cardiac arrest protocols and protocols on cooling and rewarming procedures and possible adverse events. The authors concluded that $\mathrm{TH}$ is feasible and can be used safely outside a randomized clinical trial. The ILCOR Consensus Statement on Post-Cardiac Arrest Syndrome (Neumar et al., 2008) gave TH an out-of- hospital post resuscitation care recommendation of Class IIA and in-hospital recommendation of Class II B.

In 2009, representatives from five international critical care professional societies (Nunnally et al., 2011) convened topic specialists and a non-expert jury to review, assess, and report on studies of targeted temperature management (a.k.a. TH) and to provide clinical recommendations. The report was published in 2011. The authors recommended changing the name of TH to "Targeted Temperature Management" (TTM). They reasoned that the term TH implies a positive clinical outcome that cannot be assumed. The jury strongly recommended TTM to a target of $32^{\circ} \mathrm{C}-34^{\circ} \mathrm{C}$ (mild hypothermia) as the preferred treatment versus unstructured temperature management in out-of-hospital adult cardiac arrest victims with SROC from VFib 
and still unconscious.

In 2010, the AHA increased the strength of the use of TH or targeted temperature management in Part 9: Post-Cardiac Arrest Care: 2010 AHA Guidelines for Cardiopulmonary Resuscitation and Emergency Cardiovascular Care (American Heart Association, 2010) for outof-hospital V-fib Cardiac Arrest Comatose Adult to AHA Class I (LOE B), stating that the benefits outweighed the risk and the treatment should be administered. They weighted the evidence as level $\mathrm{B}$, stating that studies using concurrent controls without true randomization support the use of the treatment. This level falls below the highest level of evidence of randomized controlled trials but constitutes strong evidence. They further rated the use of TH for In-hospital VF/Vfib Cardiac Arrest Comatose Adult and other rhythms as well as out-ofhospital pulseless electrical activity (PEA) or asystole as AHA Class II b (LOE B) and recommended in favor of the treatment as being useful and effective. They also included recommendations for the identification and treatment of acute coronary syndromes (ACS) which includes PCI.

These recommendations overall represent strong broad support for $\mathrm{TH}$ as a standard of care in post cardiac arrest care for adults.

\section{Improving Patient Outcomes: Use of Cardiac Regional Centers}

Out of hospital cardiac arrests are considered to be an important public health problem.

There are large and important regional variations in outcomes. Survival rates vary widely among patients with out of hospital cardiac arrest treated by emergency medical services (EMS) and among patients transported to the hospital after return of circulation. Many regions lack a well coordinated approach to post cardiac arrest care. Effective hospital based interventions for out of hospital cardiac arrest exist but are used infrequently. The barriers to imple- 
mentation include lack of knowledge, experience, personnel, resources, and infrastructure. How can systems be optimized to give patients the best possible outcomes following out of hospital cardiac arrest? There is a well defined relationship between an increased volume of patients or procedures and better outcomes among providers and hospitals for several other clinical disorders including stroke, myocardial infarctions, and trauma. The US system of care includes primary (clinics and walk-in health care centers), secondary (community hospitals), and tertiary levels (regional and university medical centers) of care. Regional centers have improved provider experience and patient outcomes for patients with life threatening trauma or ST segment myocardial infarction. Could more patients survive OOHCA if they were taken to regional centers instead of first being treated at community hospitals?

Investigators Davis and colleagues (2007) conducted a prospective observational study in a large urban EMS system in San Diego California, over an 18 month period, and utilizing 1,141 cardiac arrest patients. The study objective was to explore the potential ED contribution in out of hospital cardiac arrest victims without pre-hospital ROSC and to document the relationship between transport time and outcome in patients with pre-hospital ROSC. Patients with Do Not Resuscitate (DNR) orders were excluded from the study. Patients declared dead in the ED, and those who died following hospital admission and survived to hospital discharge were compared with regard to transport intervals. In addition, the patients were stratified by transport interval and compared with regard to final disposition. Median transport interval was used as a threshold. Finally, receiver-operator curve (ROC) analysis was used to explore the predictive ability of transport time on survival to hospital admission for transported patients with ROSC. They used the median transport interval of seven minutes as the threshold. ROC analysis showed an absence of predictive ability for transport time with regard to survival to hospital 
admission.

The authors concluded that continuing resuscitative efforts on scene in the field for 20 minutes as suggested by the EMS guidelines is preferable to rapid transport times. The quality of chest compressions is critical early in resuscitation and deteriorates during transport. The researchers suggested that maximizing resuscitative efforts in the field would likely decrease the opportunity for successful ED resuscitation when pre-hospital efforts are successful. They concluded that, in 2006, where few centers were utilizing TH routinely, there remained no optimal strategy for cooling. They further stated that evidence of coronary thrombosis in association with OOHCA and the emergency reperfusion strategies available make getting OOHCA patients to centers that could deliver these treatments a priority. The researchers reasoned that OOHCA patients with ST segment myocardial infarction may benefit from prompt PCI to improve cardiac function, thereby increasing chances of survival. Since not all hospitals had interventional cardiac catheterization capability, patients should be transported to medical centers able to provide that treatment. The researchers reasoned that centers with greater experience in resuscitation and post cardiac arrest care may lead to better outcomes. Not all hospitals have the capability for interventional cardiac medicine. They advocated creating designated regional receiving facilities (with interventional cardiac facilities and $\mathrm{TH}$ ability) which would then gain greater experience with this patient population.

In 2010, the AHA (Nichol et al., 2010) issued a policy statement also advocating regionalization of cardiac centers in a policy statement on regional systems of care for out of hospital cardiac arrest. Advantages of a regionalized approach to post cardiac arrest care include that centers treating the largest number of post cardiac arrest patients will have the greatest resources, the most experience, and more successful patient outcomes. The 2010 AHA 
Post Cardiac Arrest Care Guidelines for Cardiopulmonary Resuscitation and Emergency Cardiovascular Care (AHA, 2010) cited the Bernard (2002) and HACA (2002) prospective clinical trials that suggested that $\mathrm{TH}$ outcome achieved within two hours or at a median of eight hours after ROSC demonstrated better clinical outcomes. This data suggests that there is time to transport OOHCA patients to a regional center for PCI and TH without sacrificing patient survival and good neurological outcomes.

\section{Identifying the Needs of Families}

TH can offer hope to families of OOHCA patients. However, the final outcome of the treatment will not be known for several days or longer. Families must live with uncertainty and stress as they wait for the treatment to finish and determine the patient outcome. Nurses must cope with many challenges and emotional needs of family members. Families who experience a loved one in a sudden death situation experience extreme stress and grief. They have both knowledge needs and emotional needs, and look to the nursing and medical staff to provide information, emotional support, and hope. Because the TH patients' outcomes will not be known for more than 72 hours, families may experience significant stress during this period (Bond, Drager, Mandleco, \& Donnelly, 2003; Hickman \& Douglas, 2010). As part of a family-centered care philosophy, the needs of the families must be identified and techniques used to provide emotional support and increase communication between medical personnel and family members. The American College of Critical Care Medicine Task Force (2004- 2005) provides clinical guidelines for the support of the family in the patient-centered intensive care unit (Davidson et al., 2007).

Lof, Sandstrom, and Engstrom (2010) conducted a qualitative study of relatives' experiences following a family member undergoing TH. In their interviews with families, the authors 
noted that the critical care unit became the center of families' lives, and other family activities stopped. Family members relied on the doctors and nurses for daily information and support. Recovering patients relied on family members to offer support in their recovery. Family members validated the patients' importance as a family member and also serve as an advocate for the patient. The authors noted that if family members were to be able to support the patient, then they in turn must receive support from the staff. A study by Bond and colleagues (Bond, Drager, Mandleco, \& Donnelly, 2003) that examined the needs of family members of patients with traumatic brain injury identified similar concerns.

Hickman and Douglas (2010) examined the impact of critical illness on the psychological outcomes of family members. The authors reported symptoms of depression, anxiety, and post traumatic stress in family members following a traumatic event such as cardiac arrest. They suggested that the stress of family members' illness may adversely affect the families' ability to understand and grasp what medical information that is being given to them and also the ability to make decisions for the family member that may not be reflective of the family member's wishes. Hickman and Douglas suggested that the goal of family-centered care is to recognize the needs of both the family and the patient simultaneously during critical illness. Family members need to be viewed not as visitors but potential caregivers, decision makers, and vulnerable persons that live with psychological stress and uncertainty.

While TH may offer the hope of a good neurologic outcome for patients, the reality is that some will survive with devastating brain damage (Messner, Reck, \& Curci, 2005). Several studies (Messner, et al., 2005; Nelson, Walker, Luhrs, Cortez, \& Pronovost, 2009) have found families of these patients, once identified, need additional support. A poor neurologic outcome can be devastating to a family, both emotionally and financially. Their family member may still 
survive, but never cognitively be the same person. These families need support from nurses, physicians, clergy, family advocates, social service and case management in determining placement and accepting a poor outcome (Messner et al., 2005).

Families need planned interventions aimed at helping them cope. These interventions include printed informational brochures on procedures, the use of family meetings and regular communication of the plan of the day, emotional support from the staff, and open visitation policies (Messner et al., 2005). A study by Messner and colleagues (2005) revealed increased patient satisfaction with information brochures in the Emergency Department developed to explain the way that patients were seen for medical attention. Nelson and colleagues (Nelson, Walker, Luhrs, Cortez, \& Pronovost, 2009) found that family meetings are an essential forum for communication and decision making about appropriate goals for the care of ICU and ER patients.

\section{The Effect of Collaborative Practice and Teamwork on Patient Outcomes}

ER and ICU Nurses are critical to the successful implementation of TH. How then does education help nurses to succeed within the system? Zack and colleagues (2002) noted that by focusing education on the importance of interdisciplinary cooperation, the education program is able to highlight the key role that nursing plays in identifying patients that might benefit from $\mathrm{TH}$ as well as the importance of teaching families. Knowledge of evidence-based practices empowers nurses to recognize and utilize the ventilator associated pneumonia (VAP) and central line best practices, sedation protocols, and intricacies as well as complications from TH as they care for these patients. Roberta Kaplow suggested that expert knowledge allows nurses to prioritize patient care, utilize critical thinking, and communicate concerns clearly with physicians and other colleagues (Kaplow \& Hardin, 2007). Research has shown that education 
empowers nurses by increasing nurses' confidence in their practice and increasing effective interaction with other members of the healthcare team.

Gerardi (2004) and Stein-Parbury and Liaschenko (2007) studied the relationship between complex health care systems and the interdependencies that enable the coordination of resources and information. Gerardi (2004) theorized that the interdependencies require a strong working relationship for care to be delivered within complex systems. The ICU and the Emergency Room are perfect examples of complex systems. The presence of poor working relationships impacts the staffs' ability to provide quality care and affects recruitment and retention. The complex needs of critically ill patients increase the need for good nurse-physician collaboration. Knaus and colleagues (Knaus, Draper, Wagner, \& Zimmerman, 1986) found improved patient outcomes were due not to structural elements of the ICUs but the process of teamwork and the collaboration between nurses and physicians. Baggs and colleagues (Baggs, Schmitt, Mushlin, Mitchell, Eldredge, Oakes, \& Hutson, 1999) and others have documented the effect of good collaboration on positively impacting patients' outcomes in major medical centers. A collaborative practice model of mutual respect, good communication, and a team approach have been shown to improve patient outcomes.

No one discipline is solely responsible for the care of the intubated, sedated, paralyzed, and cooled patient. Several studies examined the interrelationship between physicians, nurses, and respiratory therapists and the effect on patient outcomes (Smyrnios et al., 2002; Stein-Parbury \& Liaschenko, 2007). Education should not be limited to the nursing staff. In two studies of VAP multidisciplinary education programs, researchers noted a relationship between a multidisciplinary education program for critical care physicians, nurses, and respiratory therapists and the decrease of VAP cases (Kaye et al., 2000; Zack et al., 2002). The studies also showed in- 
creased compliance and improved patient outcomes when evidence-based protocols were used in a multidisciplinary approach. All members of the ICU team, including nurses, physicians, and respiratory therapists need to understand the practice guidelines, integrate them into daily practice, and communicate daily goals to other members of the ICU team. The researchers found that the best patient outcomes occurred when there was a comprehensive education program implemented for all ICU and ER staff and ancillary services.

In summary, effective communication of patient treatment goals between ER team members and ER/ICU has been shown to increase interdisciplinary collaboration and improve patient outcomes.

\section{The Role of the Clinical Nurse Specialist in Therapeutic Hypothermia}

The role of the clinical nurse specialist (CNS) began in 1950. The goal was to prepare inpatient bedside nurses who would serve acutely ill patients via consultation and direct care (Cohen, Crego, Cumming \& Smyth, 2002). CNSs were considered expert clinicians, consultants, educators, and researchers. The role of CNSs since 1950 has changed as the healthcare climate has changed.

The Synergy Model (Appendix A) developed by the AACN Certification Corporation in 1998 (Curley, 1998) was introduced as a way of linking certified nursing practice to patient outcomes. Yet, in the 1980 's, many CNSs were cut from hospital staffs as some responsibilities shifted to nurse managers and with the abandonment of some of the traditional roles of educator and researcher. Jobs for CNSs all but vanished. By 2002, as hospitals began to hire new graduate nurses to work in specialty areas, they had a sudden need for intense education and orientation coordinated by CNSs. In addition, hospitals were seeking to improve patient outcomes while containing operating costs, and hospitals began hiring CNSs again (Cohen, Crego, Cum- 
ming, \& Smyth, 2002).

CNSs now function on an organization wide level, and are expected to assist multiple units, facilitate process changes on a system wide level, and expand their knowledge of specific patient populations or services offered within specified areas. Hospital certifying organizations such as the Joint Commission on Accreditation of Healthcare Organizations (TJC) are increasingly demanding measurable positive patient outcomes that are often CNS driven. CNSs can also play an important role in creating healthy work environments by fostering collaborative relationships (Appendix B). The American Association of Critical Care Nurses (AACN) (2002) defined the seven key elements of the clinical nurse specialist (CNS) practice to include:

1) Demonstrating clinical expertise;

2) Integrating care across the continuum;

3) Using evidence-based practice to design, revise, and evaluate innovations in clinical practice effecting patients and care delivery systems to improve outcomes in a cost effective manner;

4) Facilitating learning based on learner needs by developing innovative educational programs for patients, families, nursing personnel, other health care providers and communities;

5) Collaborating with multiple disciplines to facilitate intra- and interdisciplinary best practice;

6) Assisting patients and families to navigate a complex healthcare system;

7) Creating environments, through mentoring and system changes that empower nurses to develop caring practices, alleviate patient suffering, facilitate ethical decision making for themselves and their patient/families, respond to diversity and serve as a strong patient advocate.

TH utilizes the role of the CNS through meeting staff and family educational needs, facilitating 
intra- and interdisciplinary cooperation and best practice, improving patient outcomes, and improving patient and family satisfaction (Fulton, Lyon \& Goudreau, 2010; Kozlk, 2007; McKinley, 2007). The development and implementation of $\mathrm{TH}$, multidimensional educational approaches and evaluation of the change process are examples of how the CNS can positively impact TH care and outcomes. The purpose of this project was to develop an educational program for critical care nurses caring for patients undergoing $\mathrm{TH}$.

Next, the theoretical frameworks that were used to guide this program development will be reviewed. 


\section{Theoretical Frameworks}

Two theoretical frameworks supported the development of the education program. The Synergy Model was used to identify nursing educational needs, and Robert Knowles' Theory of Adult Learning was used to structure the educational program and to encourage motivation of the participants to actively learn.

\section{The Synergy Model}

The Synergy Model (Kaplow \& Hardin, 2007; McEwen \&Wills, 2007; Morton \& Fontaine, 2009) was used to guide the student developer's role as a facilitator of learning and also to guide construction of the learning objectives for the learning module. The Synergy Model was developed in 1998 by a task force of the American Association of Critical Care Nurses (AACN) led by Dr. Martha Curley (Curley, 1998) in order to restructure the AACN certification examination by identifying essential nurse competencies. This model is identified as a middle range theory and is applicable to all practice settings. The objective was to move away from task orientation toward recognition of the essential relationship between the nurse and the patient. The model acknowledges the importance of nursing care based on needs and is based on the premise that patients' outcomes are optimized when patient characteristics match nurses' competencies. The model states that true synergy can occur only when all three components work together synergistically to support the patient (Appendix A).

The Synergy Model identifies patient characteristics, nurse competencies, and healthcare system characteristics. Each patient brings a unique set of characteristics which should be assessed. The model originally identified 13 patient needs and was later distilled to eight concepts. Patients fluctuate along these continuums which are believed to reflect universal needs of patients. There are also eight patient characteristics including: resiliency, vulnerability, 
stability, complexity, resource availability, participation in care, participation in decision making and predictability.

Next, there are eight nurse characteristics including: clinical judgment, advocacy and moral agency, caring practices, collaboration, systems thinking, response to diversity, facilitation of learning and clinical inquiry, each with a specific definition. The nurse characteristics should be closely matched to the needs/characteristics of the patient in order to obtain optimal outcomes. The nurse characteristics affect each patient characteristic, resulting in helping the patient and family progress toward a positive outcome. The nurse characteristics have the potential to strengthen the patient characteristics, thus enabling the patient/family to achieve optimal outcomes. The proposed educational program will address nurse strengths to optimize patient outcomes (Kaplow, 2002).

The CNS is an organizational leader who functions within the patient/client, nursing personnel and organizational spheres of influence (Appendix B). The role of the CNS as defined in the Synergy Model encompasses the seven key elements of the CNS practice (Fulton, Lyon, \& Goudreau, 2010; McKinley, 2007) and includes demonstrating clinical expertise, integrating care across the continuum, using research-based evidence to design, revise, and evaluate innovations in clinical practice and improve outcomes in a cost-effective manner. CNSs facilitate learning based on learner needs by developing innovative educational programs for patients, families, nursing personnel, other health care providers and communities. The CNS collaborates with multiple disciplines to facilitate intra- and interdisciplinary best practice and assists patients and families to navigate a complex healthcare system. The CNS creates environments that empower nurses to develop caring practices, alleviate patient suffering and facilitate ethical decision making for themselves and their patients and families. CNSs encourage nurses to respond to 
diversity and serve as strong patient advocates.

The CNS role in the development and implementation of an TH policy and this educational program used an interdisciplinary approach as well as the CNS' expert knowledge, evidencebased best practice and specialty skills.

\section{Knowles Theory of Adult Learning}

Knowles' Theory of Adult Learning (Knowles, 1973) was the theoretical framework used to guide development and implementation of the learning module. Knowles studied the field of adult learning and identified six characteristics of adult learners:

1) Adult learners are autonomous and self-directed. They need to direct their learning themelves. Teachers need to allow the learner to assume responsibility for class participation and projects. Teachers need to be facilitators, guiding the learners toward knowledge rather than just lecturing. They need to show the learners how the class will help them reach their goals;

2) Adult learners have life experience and previous education that they draw from daily. Teachers need to draw on that experience and relate concepts and theories to the participants so that the learner realizes the value of the learning;

3) Adults are goal oriented. They need structure and goals. They expect that they will accomplish a certain level of learning within a period of time. Their time is valuable. Teachers need to identify objectives and clearly describe the projects expected for completion of the program;

4) Adult learners are relevancy-oriented. They need to see a reason to learn. Learning must relate to work or other responsibility. The teacher must relate concepts to relevant outcomes and projects; 
5) Adults are practical. Teachers must clearly relate a lesson to a skill needed for a job or objective;

6) Adult learners need to be shown respect. Adult learners have experience and want that to be respectfully acknowledged through their participation. As adult learners, nurses need to be self-motivated to learn.

Next, the methods used to develop the educational program will be identified. 


\section{Methods}

\section{Purpose}

The purpose of this project educational was to develop an educational program for critical care nurses caring for patients undergoing $\mathrm{TH}$.

\section{Design}

This program development project used a pre-test, intervention, and post-test design.

\section{Sample and Site}

The site was Newport Hospital (NH), a 129-bed Magnet certified community hospital, located in Newport, Rhode Island. The target population included all critical care and emergency room nurses employed at NH. The NH ED employed 32 nurses and the ICU employed 25 nurses at the time of the study. A convenience sample of nurses willing to attend the educational program was recruited.

\section{Needs Assessment}

Background. In August, 2009, the student investigator attended a two day seminar at the University of Pennsylvania on TH taught by the faculty of the University of Pennsylvania Medical School Resuscitation Science Center. The faculty teachers were experts in TH and were widely published in numerous professional peer reviewed journals. The seminar included small group simulation practice sessions with the programs' faculty. This program served as an excellent introduction to $\mathrm{TH}$.

In August 2010, NH administrators and physician identified the need for the use of TH as part of their post cardiac arrest care, and accordingly purchased Blanketrol III TH equipment. This author's clinical preceptor and CNS for the Ed and ICU at NH, Kathy Bergeron, MS, APRN began staff education on TH assisted by the Blanketrol sales representative. 
This student investigator was assigned to complete two clinical semesters at NH during the fall of 2010 and spring of 2011, as part of my graduate clinical experience. This writer had identified interest in TH to professor Dr. Cynthia Padula while taking Nursing 509, Professional Project Seminar over the summer of 2010. This student wanted to have a clinical experience where TH would be practiced. It was agreed that the writer would assist with the implementation of TH with Kathy Bergeron in the spring of 2011. From the beginning and throughout this project, Kathy was tremendously helpful in sharing her knowledge of Newport hospital and provided indispensable support and guidance.

Because TH policies were new to regional ICUs, this writer visited the Miriam Hospital Coronary Care Unit (CCU) in Providence, RI, where TH was currently being performed. TH policies from two Lifespan partner hospitals, Miriam Hospital and Rhode Island Hospital, were reviewed. The University of Pennsylvania Resuscitation Science web site was accessed for copies of other hospital TH policies as well. This author was invited to observe and participate in the NH ED TH Committee meetings in December 2010 with Kathy Bergeron, the clinical preceptor. As a result of those meetings, a Family Education Brochure was developed, which was presented to and approved by the NH TH policy committee (Appendix C). Kathy Bergeron later developed the TH vital sign sheet.

The existing TH policy and the on-going education needs of the ED and ICU were identified and discussed with my preceptor. This author suggested to Kathy that the ICU and ED staff needed a TH resource and subsequently developed the Therapeutic Hypothermia Unit Resource Manual utilizing my literature search and examining the staff nurse learning needs. The manual included such documents as a copy of the TH policy, and an educational slide presentation that served as the intervention for this project. Also included were the most recent 
2010 ACLS protocols, current articles from nursing and medical journals on TH application, family support, the TH Vital Sign Sheet, and contact information for the CNS. Eventually, a copy of the AACN Family Conference Guide (AACN, 2009) (Appendix D) and the Family Education Brochure were added following the completion of this project.

In December 2010, NH approved the final version of the Therapeutic Hypothermia Post Cardiac Arrest Policy, which was first implemented in January, 2011. Shortly after, nurses expressed concern that they did not feel comfortable with the policy. The student writer developed a brief "Just in Time" educational Power Point of TH containing key points approved by Kathy Bergeron. Initially, the "Just in Time" education program, consisting of a 10 minute inservice, was provided to available nurses in the ED and ICU at random times by both the student writer and Kathy Bergeron. The ED and ICU nurses were given a 10 minute in-service together with copies of the "Just in Time" Power Point, a printout of the TH policy and a copy of the TH vital sign sheet. A copy of the TH Unit Resource Manual was left in each unit.

Despite the AHA mandate for all hospitals to develop policies for TH as part of their post cardiac arrest care, many of those patients who have cardiac arrest from VF or VFib with ROSC and indications of a STEMI would ultimately be transported to the nearest interventional cardiac catheterization lab. An ED in small, community-based facility like NH may begin cooling prior to transport, but often not complete the TH protocol, resulting in $\mathrm{TH}$ being very infrequently practiced. The ICU staff may only see one or two in patient cardiac arrest with ROSC who are cool a year. This situation will likely leave the ICU staff without much practice in this technique and leave them with many unanswered questions. Clearly this situation necessitated a plan for on-going, updated education if the procedure was to be effectively performed.

The annual mandatory unit education was conducted in April of 2011, and a TH presenta- 
tion was included. Kathy offered this author the opportunity to give the presentation on TH. A CPR mannequin was utilized with the TH cooling wraps to familiarize the nurses with the application of the wraps. The student writer made two trifold educational displays to use with the presentation and to keep for use in the units. The nurses were encouraged to be "hands on" with the equipment. Plans were made to schedule a one hour TH educational program later that year. That program served as the educational intervention for this project and was planned using the Plan-Do-Study-Act quality improvement model described below.

\section{Plan-Do-Study-Act (PDSA)}

The Plan-Do-Study-Act (PDSA) model (Appendix E) was developed by W. Edwards Demming (Scherkenbach, W. W., 1991) and used for testing for change in "real" work settings (IHI, n.d.). This is the scientific method for action-oriented learning in work place settings. The PDSA model is short-hand for PLAN-DO-STUDY-ACT. In this model, a change is planned and implemented. The results are observed and the quality improvement (QI) team takes action based on what is learned. The effect of small improvements, such as an education program on TH, may lead to further QI projects such as "Just in Time" education on TH and inclusion in unit competencies. The PDSA model is the suggested theoretical framework for the IHI QI measures. It is also widely used in many healthcare specialty organizations such as oncology and HIV patients. It is the model for the United Kingdom's National Primary Care System and National Health Service (NHS Institute for Innovation and Improvement, 2007).

Two TH cases had been completed at NH. The CNS and student investigator analyzed the role of nursing in those two cases and determined that there was a need for a more comprehensive education program. The PDSA model was used to develop a plan (Appendix F) for the TH educational program. 


\section{Intervention}

Plans were made for the student investigator to teach a one hour TH educational program, derived from the literature, clinical experience, and needs of the institution. The educational content and learning objectives of the program are illustrated in Table 1. Educational materials

Table 1

TH Program: Time Frame, Content, Objectives, and Teaching Strategies

\begin{tabular}{|c|c|c|c|}
\hline Time & Content & Learning Objectives & $\begin{array}{l}\text { Teaching } \\
\text { Strategies }\end{array}$ \\
\hline $5 \mathrm{~min}$ & Introduction and Pretest & & \multirow{6}{*}{$\begin{array}{l}\text { Pretest, } \\
\text { Slide } \\
\text { presentation; } \\
\text { Printed } \\
\text { Handouts. }\end{array}$} \\
\hline $5 \mathrm{~min}$ & Definition of TH and History & Define Therapeutic Hypothermia & \\
\hline $5 \mathrm{~min}$ & Discuss landmark studies & Describe two landmark studies & \\
\hline $5 \mathrm{~min}$ & Discuss post cardiac arrest syndrome & $\begin{array}{l}\text { Describe post cardiac arrest } \\
\text { syndrome }\end{array}$ & \\
\hline $5 \mathrm{~min}$ & $\begin{array}{l}\text { Discuss the neuroprotective effects of } \\
\text { TH }\end{array}$ & $\begin{array}{l}\text { Describe the neuroprotective } \\
\text { effects of TH }\end{array}$ & \\
\hline $5 \mathrm{~min}$ & $\begin{array}{l}\text { Discuss current AHA guidelines \& } \\
\text { recommendations }\end{array}$ & $\begin{array}{l}\text { Describe AHA TH } \\
\text { recommendations }\end{array}$ & \\
\hline $5 \mathrm{~min}$ & $\begin{array}{l}\text { Briefly review the Newport Hospital } \\
\text { TH policy \& equipment }\end{array}$ & $\begin{array}{l}\text { Describe the Newport Hospital TH } \\
\text { policy }\end{array}$ & $\begin{array}{l}\text { Newport } \\
\text { Hospital TH } \\
\text { Policy }\end{array}$ \\
\hline $5 \mathrm{~min}$ & $\begin{array}{l}\text { Discuss potential complications } \\
\text { associated with TH }\end{array}$ & $\begin{array}{l}\text { Describe potential complications } \\
\text { associated with } \mathrm{TH}\end{array}$ & \multirow{4}{*}{$\begin{array}{l}\text { Slide } \\
\text { presentation } \\
\text { and printed } \\
\text { handouts, } \\
\text { critical care } \\
\text { articles, } \\
\text { AACN } \\
\text { Patient Family } \\
\text { Conference } \\
\text { Guide and NH } \\
\text { TH brochure }\end{array}$} \\
\hline $10 \mathrm{~min}$ & Discuss pharmacological effects of TH & $\begin{array}{l}\text { Describe potential pharmacological } \\
\text { effects of TH }\end{array}$ & \\
\hline $5 \mathrm{~min}$ & $\begin{array}{l}\text { Review the nursing care of the } \mathrm{TH} \\
\text { patient }\end{array}$ & $\begin{array}{l}\text { Describe the nursing care of the } \mathrm{TH} \\
\text { patient }\end{array}$ & \\
\hline $5 \mathrm{~min}$ & Discuss family centered-care \& TH & $\begin{array}{l}\text { Describe family-centered care } \\
\text { Related to } \mathrm{TH}\end{array}$ & \\
\hline $5 \mathrm{~min}$ & $\begin{array}{l}\text { Questions \& Evaluations } \\
\text { CEU Certificate }\end{array}$ & & $\begin{array}{l}\text { Course } \\
\text { Evaluation and } \\
\text { CEU } \\
\text { Certificate }\end{array}$ \\
\hline
\end{tabular}


consisted of an expanded TH slide presentation and handouts. In order to help facilitate nursing involvement in family conferences, this author included the AACN Patient Family Conference Guide and the newly developed NHTH Family Brochure. The tri-fold display board illustrating and explaining the NH TH policy was also used as a visual aide. The TH Resource Notebook was on display. Due to time constraints, extensive discussion and presentation of case studies were not possible.

\section{Procedures}

Prior to beginning the study, the student investigator obtained approval from the Rhode Island College Institutional Review Board (IRB) and the Lifespan IRB. The program was submitted to the Rhode Island Nurses Association (RISNA) for continuing education approval. Nurses were recruited to the study using IRB approved flyers that were posted in the ED and ICU at NH (Appendix G). The flyer contained the student investigator's name and information, the date, time, and location of the program and information on registration. Program announcements were also made at the monthly unit councils.

Potential participants were told that their attendance at the sessions was voluntary and that, if they decided to participate, they would be asked to complete the pre- and post-tests, which would remain anonymous and confidential. No compensation would be made to study participants. All attendees would receive educational contact hours. Nurses registered for the program by emailing Kathy Bergeron. The class information was included in the printed and online educational calendar available to all the nurses at Newport Hospital. A total of six classes were conducted over a one month time period.

Prior to beginning the educational program, an IRB approved informational letter was distributed and participant questions were addressed (Appendix H). After obtaining consent, 
participants chose an identifier from a random number chart from one to 200 and a random letter, not an initial or birth date. The identifiers were completely anonymous. Participants were instructed to write the number, letter, date, and unit on their consent, pre and posttests. Participants were instructed not to include any other identifying information.

The pre-test was administered, followed by the educational program. Participants then completed the post-test. All tests and the coded consent forms were placed in a sealed box at the end of the class.

\section{Measurement}

A pre-test and post-test was developed by the student investigator, derived from the literature and clinical experience (Appendix I). One multiple choice question was constructed for each of the major content areas taught in the educational program. The test was pilot tested with graduate nursing student colleagues and minor revisions were made based on their feedback.

\section{Post Program Evaluation}

All participants were asked to complete a program evaluation after the completion of the educational program if they wished to earn contact hours. The evaluation form used was the form required by Rhode Island State Nurses' Association (RISNA), and is illustrated in Appendix J. The Certificate of Attendance is illustrated in Appendix K.

\section{Data Analysis}

No demographic information was collected to protect the identity of the participants. Preand post-tests of participants were matched using the unique, participant-chosen key. Mean and median scores were calculated by each unit and pre and post scores of group participants were compared. Responses to the pre and posttest questions were examined by item to determine 
whether unit participants had increased their knowledge of $\mathrm{TH}$ and to determine question clarity and validity. Participant pre- and post-test scores were analyzed by unit and then compared by unit. 


\section{Results}

A total of six classes were held in various venues, as illustrated in Table 2. Some participants attended the classes, but were not ICU or ED nurses, and so were not included in the data. Twenty-four (42\%) of ICU and ED nurses out of a total of 57 participated in the study and completed the pre- and post-test; of the 24, 14 were ICU nurses and 10 were ED nurses.

Table 2

Attendance by Unit and Per In-Service.

\begin{tabular}{|l|c|c|c|}
\hline \multicolumn{1}{|c|}{ INSERVICES } & $\begin{array}{l}\text { TOTAL } \\
\text { PARTICIPANTS }\end{array}$ & $\begin{array}{l}\text { \#STUDY SUBJECTS } \\
\text { (ICU \& ER RN'S) }\end{array}$ & $\begin{array}{l}\text { INCOMPLETE STUDY } \\
\text { PAPER WORK or } \\
\text { NON- STUDY } \\
\text { PARTICIPANTS }\end{array}$ \\
\hline TH In-service & 16 & 10 & 1 \\
\hline ER In=service & 2 & 2 & 0 \\
\hline ER In-service & 3 & 4 & 0 \\
\hline $\begin{array}{c}\text { ICU Staff Meeting } \\
\text { (AM) }\end{array}$ & 9 & 4 & 0 \\
\hline $\begin{array}{c}\text { ICU Staff Meeting } \\
\text { (PM) }\end{array}$ & 9 & 2 & 0 \\
\hline $\begin{array}{c}\text { Night ICU In-service } \\
\text { Totals: }\end{array}$ & 3 & $\mathbf{2 4}$ & $\mathbf{2}$ \\
\hline
\end{tabular}

Pre- and post-test scores were first examined by individual item and by unit. ICU nurses' scores are illustrated in Table 3 (Appendix L). Only question 2 showed the ICU nurses failed to grasp the understanding of the content as evidenced by the wide variability in the answers. Scores of ED nurses pre and post are illustrated in Table 4 (Appendix M). The ED post test questions 2, 4, 5, and 8 did not show clear knowledge improvement. 
In order to compare the degree of learning between the two units, the mean and median overall scores of each of the two units were calculated and are illustrated in Table 6.

Table 6. Comparison of Mean and Median Scores Between ICU and ED Nurses.

\begin{tabular}{|l|l|l|}
\hline UNIT & MEAN & MEDIAN \\
\hline ICU Pre-test $(\mathrm{n}=14)$ & 50 & 55 \\
\hline ICU Post-test $(\mathrm{n}=14)$ & $\mathbf{7 7}$ & $\mathbf{8 0}$ \\
\hline ED Pre-test $(\mathrm{n}=10$ & 51 & 50 \\
\hline ED Post-test $(\mathrm{n}=10)$ & $\mathbf{7 3}$ & $\mathbf{7 5}$ \\
\hline
\end{tabular}

Both the ICU and ED nurses' total scores showed overall knowledge improvement with the education program. The mean ICU score on the pre-test was 50 and 77 on the post-test. The ICU nurses had a slightly higher mean and median score than the ED. The ED nurses showed slightly less increase in knowledge following the educational program. The mean ED score on the pre-test was 51 and on the post-test was 73. Overall, the two groups had similar pre-test means and both demonstrated improvement after completion of the educational session. ICU nurses improved by 27 points on average, with ED nurses improving 22 points on average. 


\section{Summary and Conclusions}

Mild TH is a highly valuable post cardiac arrest procedure that can result in preservation of neurologic function and reduction of the inflammatory effects of neurologic reperfusion syndrome following cardiac arrest. Implementing this procedure requires specific educational preparation in order for nurses to perform the procedure and anticipate the potential complications that might occur during nursing care.

The purpose of this educational project was to develop an educational program for critical care and ED nurses caring for patients undergoing TH. Twenty-four ICU and ED nurses participated in a one hour educational program developed by the student author and based on the literature, clinical experience, and assessment of the target institution. ICU and ED nurses scored low on the pre-test, 50 and 51 respectively. Both groups increased scores by over 20 points, resulting in scores of 77 and 73 respectively. Of concern to the student educator was that, though both groups improved quite dramatically, overall post test scores remained in less than desirable ranges.

Several limitations were noted in this study. The sample size was small, although the $42 \%$ $(\mathrm{N}=57)$ was believed to be a reasonable recruitment. Another limitation was that the class was limited to a one hour session. Expanded time for the education, and a follow-up session, may have yielded higher post-test scores. It should also be noted however, that not only were nurses' overall pretest knowledge surprisingly low, these nurses also have very low on-going exposure to the $\mathrm{TH}$ procedure. It was hypothesized that with expanded clinical experience to support the class content that posttest scores might have been higher.

What implications does this have for the ICU and ED at the study site? This procedure is not likely to occur often at this clinical site. From a practice as well as an education stand-point, 
infrequently used procedures can be problematic. It is recommended that $\mathrm{TH}$ reeducation should be available as a mandatory competency available on-line for the nursing staff and as a part of the unit competency skills tested annually. It is hard to know the ideal interval to reeducate nurses on a core skill, but mandatory annual unit competencies should reinforce the skill levels. Online TH education can allow nurses to access TH education at any time. Individual TH cases should be reviewed by the CNS as they occur to determine if there are any issues that need to be addressed promptly in order to resolve the problem. TH cases may be too infrequent to wait for several to occur before reviewing, and the nurses need the feedback to increase their proficiency and confidence. Online "On Demand Forms" including the NHTH Family Informational Brochure, the TH Vital Sign Sheet, and TH Policy are available for staff reference, and the Unit Resource Notebooks will provide a ready resource. The ED and ICU could also utilize unit-based $\mathrm{TH}$ champions to act as resource nurses for the staff to help in maintaining staff nurses confidence in the procedure as well as skill level. Each unit has nationally certified nurses (CCRN or CEN) who might serve as excellent resources and unit champions.

At the conclusion of the project, all TH slide presentations, the TH Family teaching brochure, resource manuals and displays were given to Kathy Bergeron for use at Newport Hospital. 


\section{Implications for Advanced Nursing Practice}

The acute care and critical care CNS occupies a unique role within the hospital system. The CNS role encompasses the three spheres: patient client, nurses and nursing practice, organizational and systems (Appendix B). To accomplish this, the CNS utilizes specialty practice, specialty standards of practice, specialty knowledge, and specialty skills and competencies. The CNS role has the potential to influence both policy and practice. As a researcher, the CNS is abreast of new standards and practices influencing patient care and outcomes. The CNS is in a position to bridge the gap between staff and administration to change policy, is a role model to the staff, and a member of the interdisciplinary team.

The role of the CNS reaches into every aspect of a healthcare organization and beyond. The AACN Advanced Practice Acute Care and Critical Care CNS Standards of Practice (2002) include assessment, diagnosis, outcome identification, planning, implementation, and evaluation. The AACN CNS standards for assessment include collecting data relevant to the three spheres of influence. As a diagnostician, the CNS analyzes the assessment data to determine the needs of patients, family members, nursing staff, and organizational systems. The CNS effectively plans and implements the interventions identified in the plan of care for the patient and family, nursing personnel, and organizational system. The CNS evaluates progress toward attaining the expect-ed outcomes for patients, family members nursing personnel and the organizational system.

Development of the TH education program is an example of the critical role of the Advance Practice Acute Care Critical Care CNS in the ED and ICU. This project illustrates how the CNS can positively impact outcomes in all three spheres of influence. The CNS role within the institution is broad and includes but is not limited to developing hospital policy, setting goals and 
standards, educating and evaluating staff, advocating for patients and families, and working to assure positive patient outcomes. The advanced practice CNS can provide indispensable support to staff and patients and families as well as influence patient out-comes and system changes. CNSs play an integral role in quality and safety within institutions and beyond.

At the broader level, CNSs have the ability to impact national policy and help to set national agendas. CNS participation in key organizations such as the AHA can help to influence policy related to TH and other key areas moving forward. Advanced practice nurses have been extremly influential in shaping public policy around clinical prevention. While significant improvements in cardiovascular disease outcomes have been realized, much work remains to be done to improve the health of the nation. 


\section{References}

Acierno, L.J. \& Worrell, L.T. (2007). Profiles in Cardiology: Peter Safar, Father of modern cardiopulmonary resuscitation. Clinical Cardiology, 30, 52-54.

Al-Senani, F. M., Graffagnino, C., Grotta, J.C., Saiki, R., Wood, D. Chung, W., ... Collins, K.A. (2004). A prospective, multicenter pilot study to evaluate the feasibility and safety of using the CoolGard System and Icy catheter following cardiac arrest. Resuscitation, 62:143-150. doi:10.1016/j.resuscitation.2004.02016.

American Association of Critical Care Nurses (2002). Scope of practice and standards of professional performance for the acute and critical care clinical nurse specialist. Aliso Viejo, CA: American Association of Critical Care Nurses.

American Nurses Credentialing Center (2012). Magnet Recognition Program. Retrieved December 8, 2012, from http:// www.nursecredentialing .org.

American Heart Association (2009). 2009 Update: Out of hospital cardiac arrest -Statistics. Retrieved April 24, 2011, from AHA web site: aha.com.

American Heart Association (2010). Part 9: Post cardiac arrest care: 2010 American Heart Association guidelines for cardiopulmonary resuscitation and emergency cardiovascular care. Circulation 2010, 122; S768- 786. doi:10.1161/CIRCULATIONAHA.110.971002.

Antman, E.M., Anbe, D.T., Armstrong, P.W., Bates, E.R., Green, L.A. , Hand, M... Smith, S.C. (2004). ACC/AHA Guidelines for the management of patients with ST-elevation myocardial infarction. Circulation, 110:e82-2292. Retrieved December 4, 2012, from http://circ.ahajournals.org/content/110/9/e82.citation.

Arrich, J. (2007). Clinical application of mild therapeutic hypothermia after cardiac arrest.

Critical Care Medicine, 35(4), 1041-1047. 
Baggs, J. G., Schmitt, M.H., Mushlin, A.I., Mitchell, P.H., Eldredge, D.H., Oakes, D., Hutson, A.D. (1999). Association between nurse-physician collaboration and patient outcomes in three intensive care units. Critical Care Medicine, 27(9), 1991-1998.

Benson, D.W., Williams, G.R.,\& Spencer, F.C., 1959). The use of hypothermia after cardiac arrest. Anesthesia Analogs, 38, 423-428.

Bernard, S. A., Gray, T. W., Buist, M. D., Jones, B. M., Silvester, W., Gutteridge, G., \& Smith, K. (2002). Treatment of comatose survivors out-of-hospital cardiac arrest with induced hypothermia. New England Journal of Medicine, 346(8), 557-563.

Bigelow, W.G. \& McBirnie, J.E. (1953). Further experiences with hypothermia for intracardiac surgery in monkeys and groundhogs. Annals of Surgery, 137, 361-365.

Boehm, J. (n.d.). A chilling review of hypothermia. Retrieved December 8, from http://Zoll. com.

Bond, A. E., Drager, C. R., Mandleco, B., \& Donnelly, M. (2003). Needs of family members of patients with severe traumatic brain injury: Implications for evidence-based practice. Critical Care Nurse, 23(4), 63-72.

Cohen, S.S., Crego, N., Cumming, R. and Smyth, M. (2002). The synergy model and the role of clinical nurse specialists in a multihospital system. American Journal of Critical Care, 11(5), 436-446.

Curley, M.A. (1998). Patient-nurse synergy: optimizing patients' outcomes. American Journal of Critical Care, 7(1), 64-72.

Davidson, J. E., Powers, K., Hedayat, K.M., Tieszen, M., Kon, A.A., Shepard, E., ... Armstrong, D. (2007). Clinical practice guidelines for support of the family in the patient-centered intensive care unit; American College of Critical Care Medicine Task Force 2004-2005. 
Critical Care Medicine, 35(2), 605-622.

Davis, D. P., Fisherb, R., Aguilarc, S., Metzd, M., Ochsb, G., McCallum-Brown, L., ... Dunford, J.B. (2007). The feasibility of a regional cardiac arrest receiving system. Resuscitation, 74(1), 44-51.

Fay, T. (1940). Clinical report and evaluation of low temperature in treatment of cancer. Procedures Interstate Postgraduate Medical Association North America, 292-297.

Fulton, J.S., Lyon, B.L. \& Goudreau, K.A. (2010). Foundations of clinical nurse specialist practice. Springer Publishing.

Georgiadis, D., Schwartz, S., Kollmar, R., \& Schwab, S. (2001). Endovascular cooling for moderate hypothermia in patients with acute stroke: First results of a novel approach. Stroke. 32:2550-2553.

Gerardi, D. (2004). Using mediation techniques to manage conflict and create healthy work environments. AACN Clinical Issues, 15(2), 182-195.

Hachimi-Idrissi, S., Corne, L., Ebinger, G., Michotte, Y., Huyghens, L. (2001). Mild hypothermia induced by a helmet device: A clinical feasibility study. Resuscitation, $51: 275-281$

Haugk, M., Sterz, F., Grassberger, M., Uray, T., Kliegel, A., Janata, A., ... Laggner, A.N. (2007). Feasibility and efficacy of a new non-invasive surface cooling device in post resuscitation intensive care medicine. Resuscitation, 75: 76-81. doi:10.1016/J.resuscitation.2007.03.001.

Heart Rhythm Foundation. http://www.heartrhythmfoundation.org/facts/scd.asp.

Hickman, R. L. \& Douglas, S. L. (2010). Impact of chronic critical illness on the psychological outcomes of family members. AACN Advanced Critical Care, 21(1), 80-91. 
Hoedemaekers, C., Ezzahti, M., Gerritsen, A. \& Van der Hoven, J. G. (2007). Comparison of cooling methods to induce and maintain normo- and hypothermia in intensive care unit patients: A prospective intervention study. Critical Care, 11: R91. doi:10.1186/cc6104.

Holtzer, M., Bernard, S.A., Hachimi-Idrissi, S., Roine, R.O., Sterz, F., \& Mullner, M. (2005). Hypothermia for neuroprotection after cardiac arrest: Systemic review and individual patient data meta-analysis. Critical Care Medicine, 33(2), 414-418.

Hovdenes, J., Lakke, J. H., Aaberge, L., Haugaa, H., \& Bugge, J. F. (2007). Therapeutic hypothermia after out-of-hospital cardiac arrest: experiences with patients treated with percutaneous coronary intervention and cardiogenic shock. Acta Anesthesiol Scandinavica, 51, 137-142. doi:10.1111/j.1399-6576.2006.01209.x.

The Hypothermia After Cardiac Arrest Study Group (HOCA) (2002). Mild therapeutic hypothermia to improve the neurologic outcome after cardiac arrest. New England Journal of Medicine, 346(8), 549-556.

Institute for Health Care Improvement. (n.d.). Changes: critical care. http://www.ihi.org/IHI/Topics/ CriticalCare/IntensiveCare/Changes.

Jennett, B. \& Bond, M. (1975). Assessment of outcome after severe brain damage. Lancet, 1(1), 480-484.

Kaplow, R. (2002). The synergy model in practice: Applying the synergy model to nursing education. Critical Care Nurse, 22(3), 77-81.

Kaplow, R. \& Hardin, S.R. (2007). Critical care nursing: Synergy for optimal outcomes. Boston: Jones\& Bartlett.

Karpovich, P.V. (1953). Adventures in artificial respiration. New York Association Press. 
Kaye, J., Ashline, V., Erickson, D., Zeiler, K., Gavigan, D., \& Gannon, L. (2000). Critical care bug team: a multidiciplinary team approach to reducing ventilator-associated pneumonia. American Journal of Infection Control, 28(2), 197-201.

Kirkland, L. L., Parham, W. M., \& Pastores, S. M. (2009). Approaching hospital administration about adopting cooling technologies. Critical Care Medicine, 37(7), S290-S294.

Knaus, W. A., Draper, E. A., Wagner, D. P., \& Zimmerman, J. E. (1986). An Evaluation of outcome from intensive care in major medical centers. Annals of Internal Medicine, 410-418.

Knowles, M. (1973). The adult learner: a neglected species, $2^{\text {nd }}$ ed. Houston: Gulf Publishing.

Kochanek, PM \& Grenvik, A. (2003). A tribute to Peter Safar, MD. Critical Care Medicine. 31(11), 2571-2573.

Koran, Z. (2009). Therapeutic hypothermia in the post-resuscitation patient: The development and implementation of an evidence-based protocol for the emergency department. Journal of Trauma Nursing, 16(1), 48-57.

Kozlk, T. M. (2007). Induced hypothermia for patients with cardiac arrest: Role of a clinical nurse specialist. Critical Care Nurse, 27, 36-42.

Liss H.P. (1986). A history of resuscitation. Annals of Emergency Medicine, 15, 65-72

Lof, S., Sandstrom, A., \& Engstrom, A. (2010). Patients treated with therapeutic hypothermia after cardiac arrest: relatives' experiences. Journal of Advanced Nursing, 66(8), 17601768. doi:10.1111./j1365-2648.2010.05352.x.

McEwan, M. \& Wills, E.M. (2007). Theoretical basis for nursing, 2nd ed. Philadelphia: Lippincott Williams \& Wilkins. 
McKinley, M.G. ed. (2007). Acute and critical care clinical nurse specialists: synergy for best practices. St. Louis: Saunders Elsevier.

Merchant, R. M., Becker, L. B., Abella, B. S., Asch, D. A., \& Groenveld, P. W. (2009). Costeffectiveness of therapeutic hypothermia after cardiac arrest. Circulation Cardiovascular Quality Outcomes, 2, 421-428.

Messner, E.R., Reck, D.L., \& Curci, K. M. (2005). Effectiveness of an education brochure in the Emergency Department. Topics in Emergency Medicine, 27(4), 251-255.

Mordecai, Y., Globus R., Dietrich W. et al. (1992). Temperature modulation of neuronal injury. In Marangos P.J., Lal H., eds. Emerging strategies in neuroprotection. Boston. Birkhauser. 289-306.

Morton, P.G. \& Fontaine, D.K. (2009). Critical care nursing: A holistic approach, $9^{\text {th }}$ ed. Philadelphia: Wolters Klewer/ Lippincott Williams \& Wilkins.

Nelson, J.E., Walker, A.S., Luhrs, C.A., Cortez, T.B., Pronovost, P.J. (2009). Family meetings made simpler: A toolkit for the intensive care unit. Journal of Critical Care, 24, 626e7626.e14.

Neumar, R., Nolan, J.P., Adrie, C., Aibiki, M., Berg, M.A., Böttiger, B.W., ... Hoek, T.V., 2008). ILCOR Consensus Statement Post-Cardiac Arrest Syndrome Epidemiology, Pathophysiology, Treatment, and Prognostication A Consensus Statement From the International Liaison Committee on Resuscitation (American Heart Association, Australian and New Zealand Council on Resuscitation, European Resuscitation Council, Heart and Stroke Foundation of Canada, InterAmerican Heart Foundation, Resuscitation Council of Asia, and the Resuscitation Council of Southern Africa); the American Heart Association Emergency Cardiovascular Care Committee; the Council on Cardiovascular 
Surgery and Anesthesia; the Council on Cardiopulmonary, Perioperative, and Critical Care; the Council on Clinical Cardiology; and the Stroke Council. Circulation, 11, 2452-2483.

NHS Institute for Innovation and Improvement (2007). Plan Do Study Act (PDSA).

Retrieved November 28, 2007 from doi: www.nodelaysachiever.hhs.uk/ .

Nichol, G., Aufderheide, T.P., Eigel, B., Neumar, R.W., Lurie, K.G., Bufalino, V. J., ... Peterson, E. (2010). Regional systems of care for out-of-hospital cardiac arrest: A policy statement from the American Heart Association. Circulation, 121, 1-23. Retrieved March 22, 2011 from doi:10.1161/CIR.0b013e3181cdb7db.

Nunnally, M. E., Jaeschke, R., Bellingan, G.J., Lacroix, J., Mourvillier, B., Rodriguez-Vega, G.M., ... Buchman, T.G. (2011). Targeted temperature management in critical care: A report and recommendations from five professional societies. Critical Care Medicine, 39(5), 1113-1125.

Polderman, K. H. \& Herold, I. (2009). Therapeutic hypothermia and controlled normothermia in the intensive care unit: Practical considerations, side effects and cooling methods. Critical Care Medicine, 37(3), 11011120.

Rosomoff, H.L. \& Holaday, D.A. (1954). Cerebral blood flow and cerebral oxygen consumption during hypothermia. American Journal of Physiology, 179, 85-88.

Safar, P. (1988). Resuscitation from clinical death: Pathophysiologic limits and therapeutic potentials. Critical Care Medicine, 16(10), 923-941.

Safar, P., Xiao, F., Radovsky, A., Tanigawa, K., Ebmeyer, U., Bircher, N., ... Stezoski, S.W. (1996). Improved cerebral resuscitation from cardiac arrest in dogs with mild hypothermia plus blood flow promotion. Stroke, 27, 105-113. 
Scherkenbach, W. W. (1991). Demings Road to Continual Improvement. SPC Press, Inc.

Sertz, F., \& Mullner, M. (2005). Hypothermia for neuroprotection after cardiac arrest:

Systematic review and individual patient data meta-analysis. Critical Care Medicine, 33(2) 414- 418 .

Smith, L.W. \& Fay T. (1940). Observations on human beings with cancer maintained at low temperatures. American Journal of Pathology, 10, 1-11.

Smyrnios, N. A., Connolly, A., Wilson, M. M., Curley, F. J., French, C. T., Heard, S. O., Irwin, R. 2002). Effects of a multifaceted multidisciplinary hospital-wide quality improvement program on weaning from mechanical ventilation. Critical Care Medicine, 30(6), 12241230.

Stein-Parbury, J., \& Liaschenko, J. (2007). Understanding collaboration between nurses and physicians as knowledge at work. American Journal of Critical Care, 16(5), 470-477.

Sunde, K. Pytte, M., Jacobsen, D., Mangschau, A., Jensen, L.P., Smedsrud, C., ... Steen, P.A. (2007). Implementation of a standardized treatment protocol for post resuscitation care after out-of-hospital cardiac arrest. Resuscitation, 73, 29-39.

Teasdale, G \& Jennett, B. (1974). Assessment of comma and impaired consciousness: A practical scale. Lancet, 2, 81-84.

Toma, A., Bensimon, C.M., Dainty, K.N., Rubenfeld, G.D., Morrison, L.J. \& Brooks, S.C. (2010). Perceived barriers to therapeutic hypothermia for patients resuscitated from cardiac arrest: A quantitative study of emergency department and critical care workers. Critical Care Medicine, 38(2), 504-509.

Varon, J., \& Acosta, P. (2008). Therapeutic hypothermia: Past, present and future. Chest Journal, 133(5) (Supplement), 1267-1274. 
Wolfrum, S., Pierau, C., Radke, P. W., Schunkert, H. \& Kurowski, V. (2008). Mild therapeutic hypothermia in patients after out-of-hospital cardiac arrest due to acute ST-segment elevation myocardial infarction undergoing immediate percutaneous coronary intervention. Critical Care Medicine, 36(6), 1780-1786.

Zack, J., Garrison, T., Trovillion, E., Clinkscale, D., Coopersmith, C.M., Fraser, V.J., Kollef, M.H. (2002). Effect of an education program aimed at reducing the occurrence of ventilator-associated pneumonia. Critical Care Medicine, 30(11), 2407-2412. 
Appendix A

Synergy Model

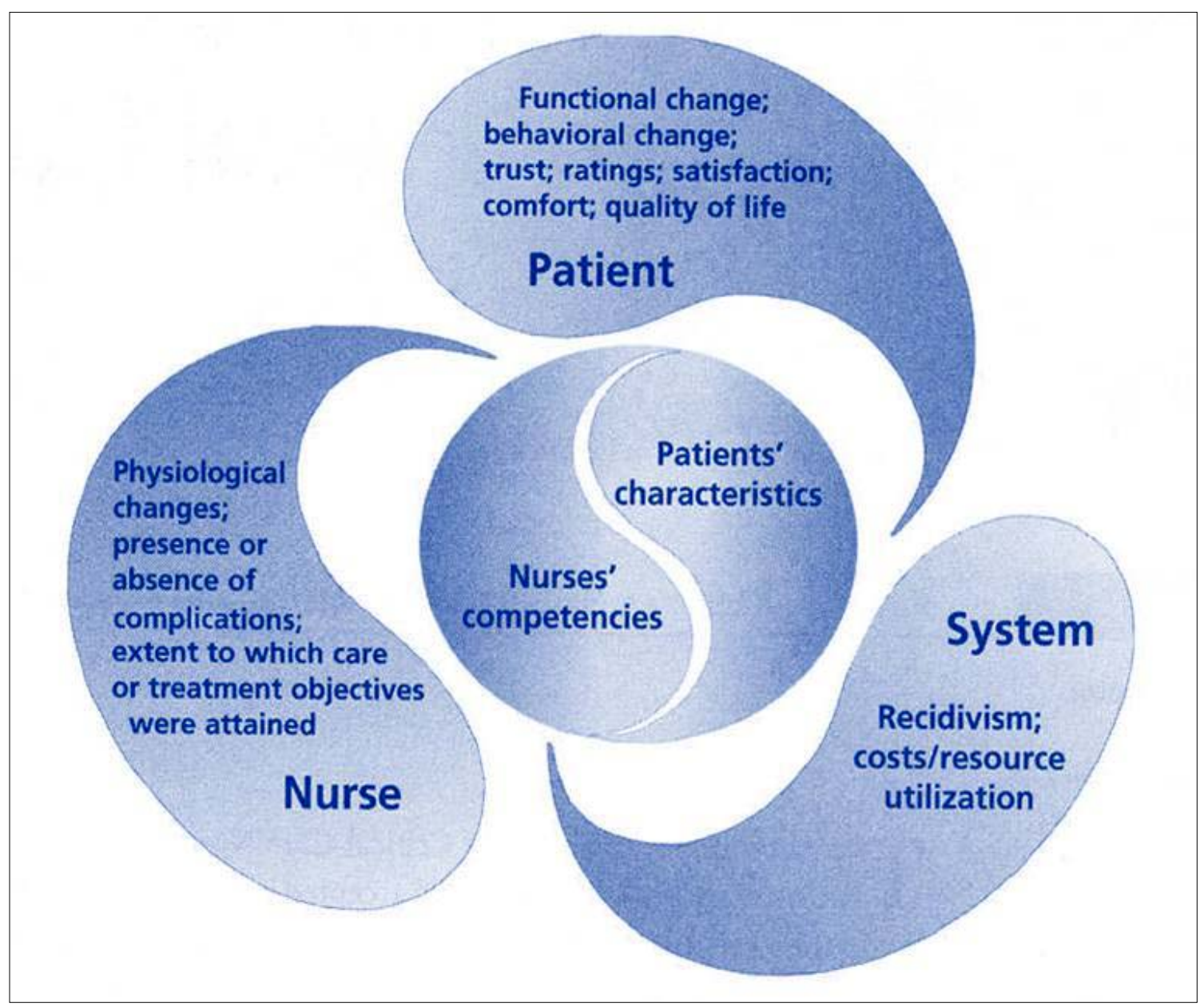

Figure 1. The Synergy Systems Model. In Morton, P.G. \& Fontaine, D.K. (2009). Critical care nursing: A holistic approach, $9^{\text {th }}$ ed. Philadelphia: Wolters Klewer/ Lippincott Williams \& Wilkins.) 
Appendix B

CNS Core Competencies

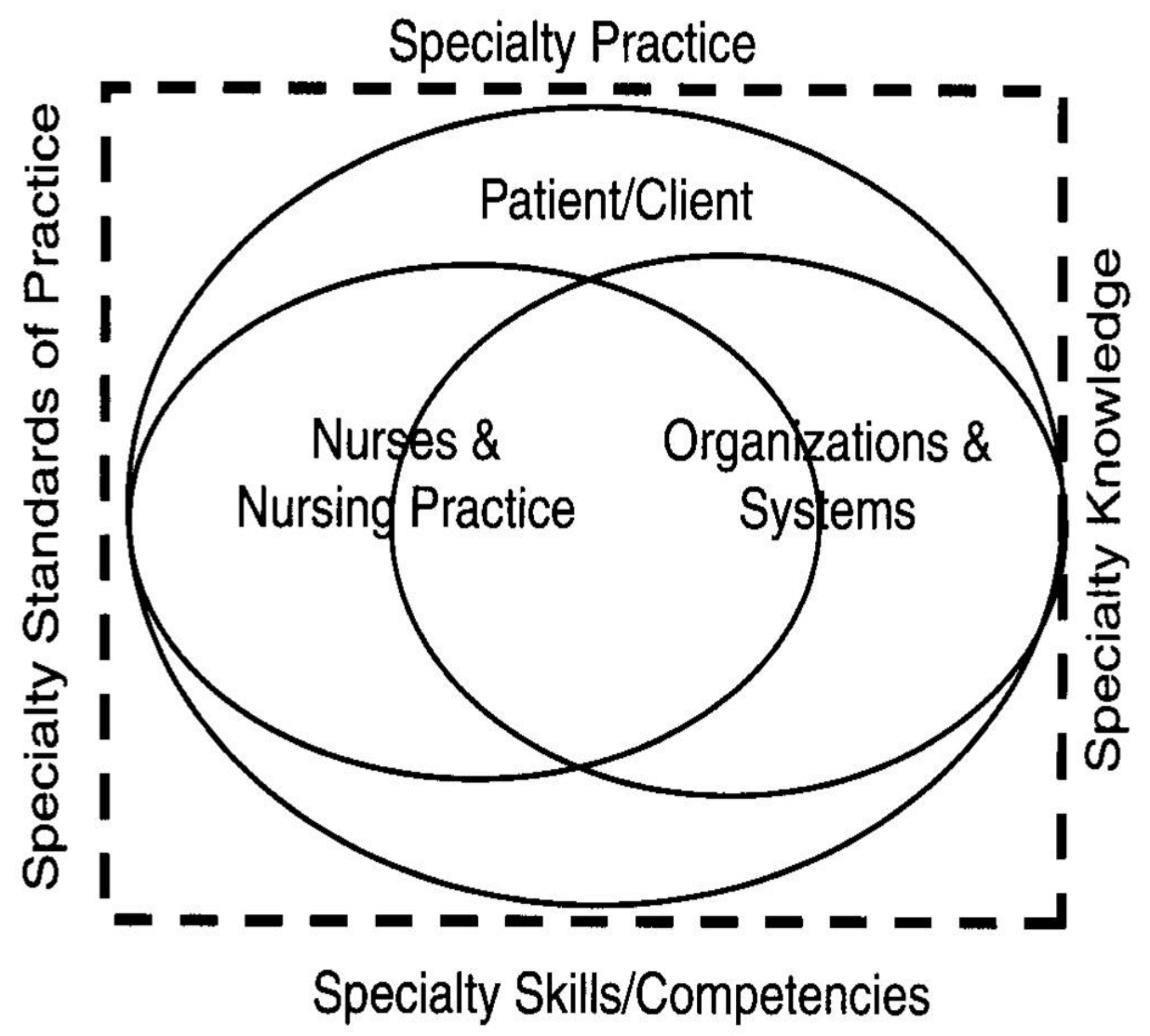

Figure 2. The Clinical Nurse Specialist core competencies in three intersecting spheres. In Fulton, J.S., Lyon, B.L. \& Goudreau, K.A. (2010). Foundations of Clinical Nurse Specialist Practice. Springer Publishing. New York.) 
Appendix C

Newport Hospital Therapeutic Hypothermia Family Information Brochure

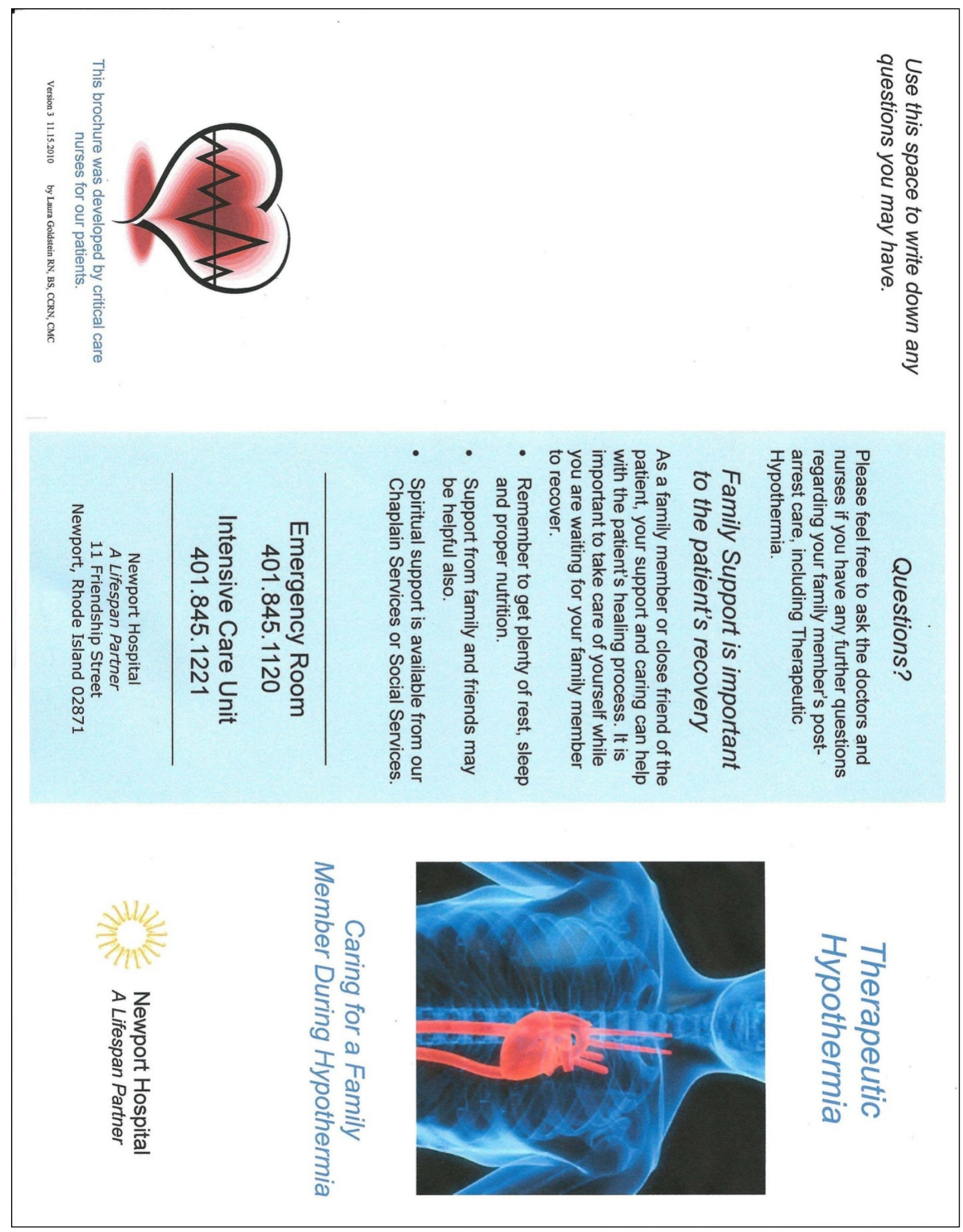




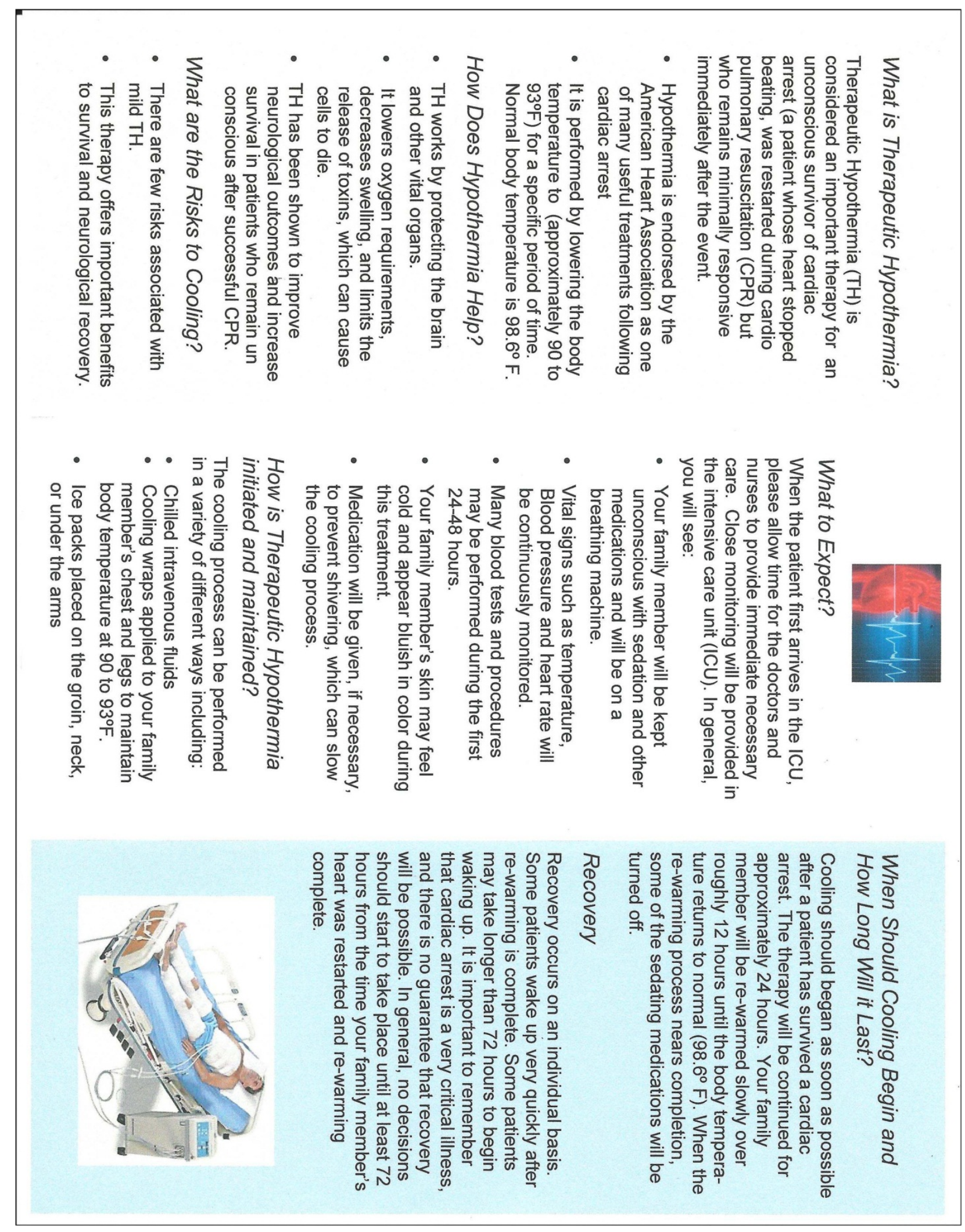




\section{Appendix D}

\section{AACN Patient Family Conference Guide}

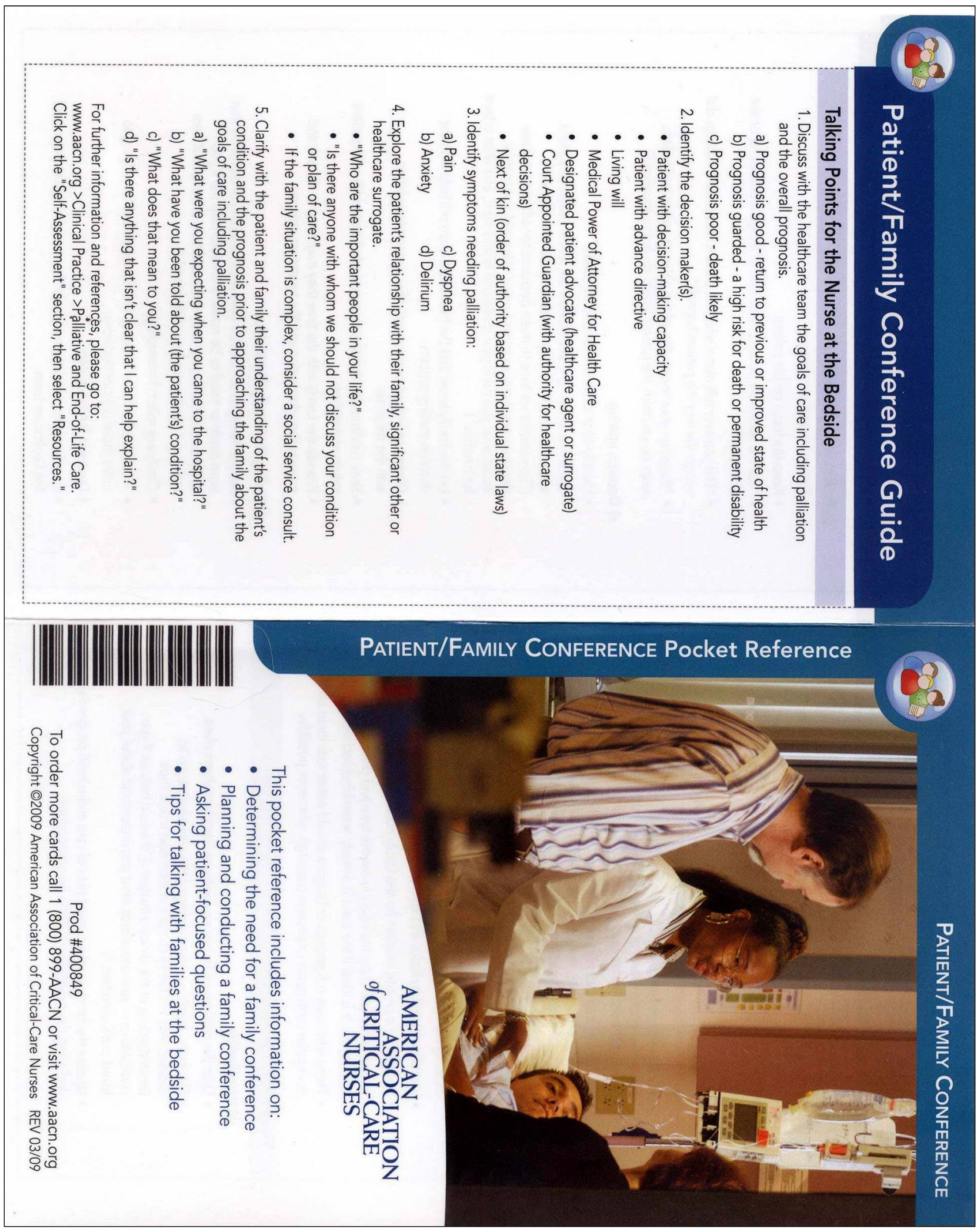




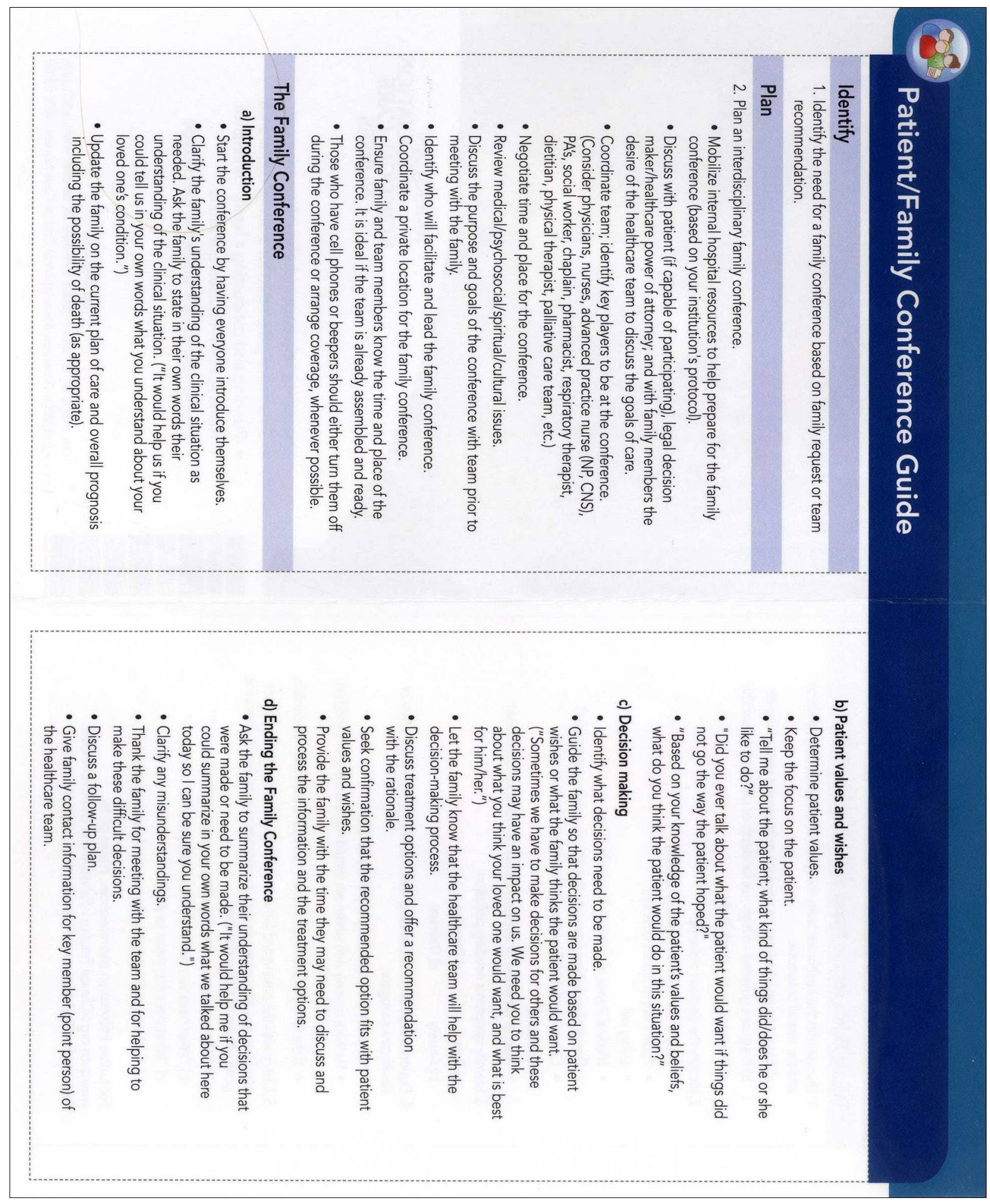


Appendix E

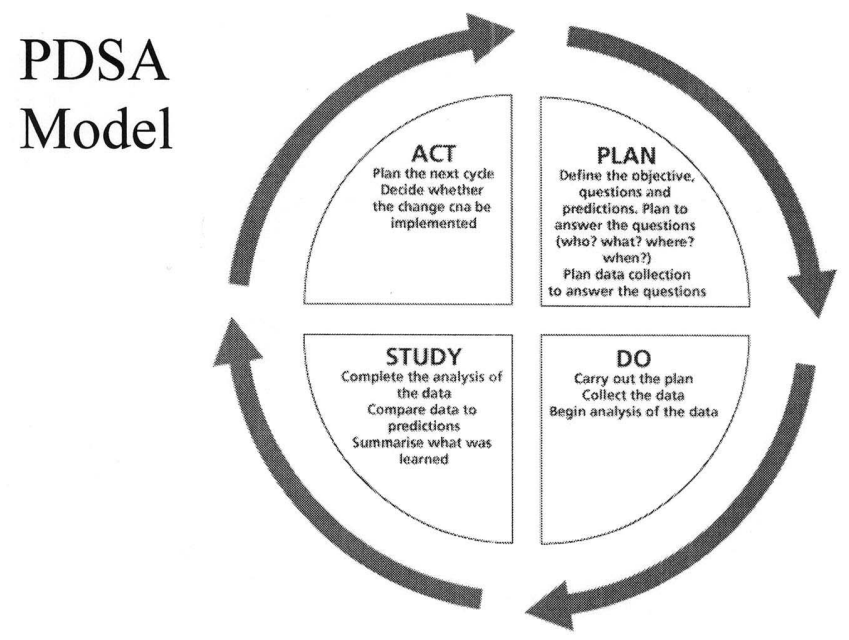

Figure 1. PDSA Quality Improvement Model (Basic).

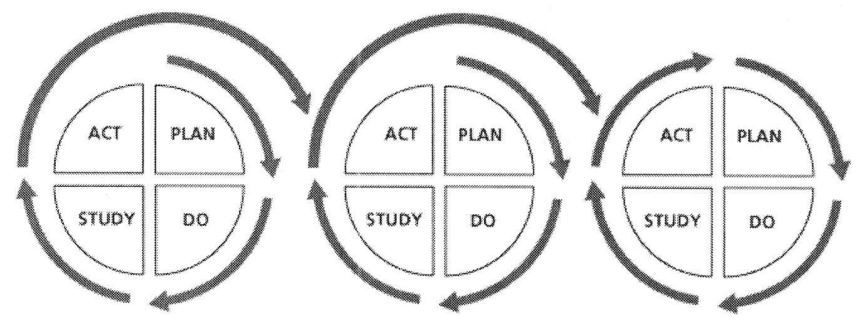

Figure 2. Implementing Change/Continuous Quality Improvement Process.

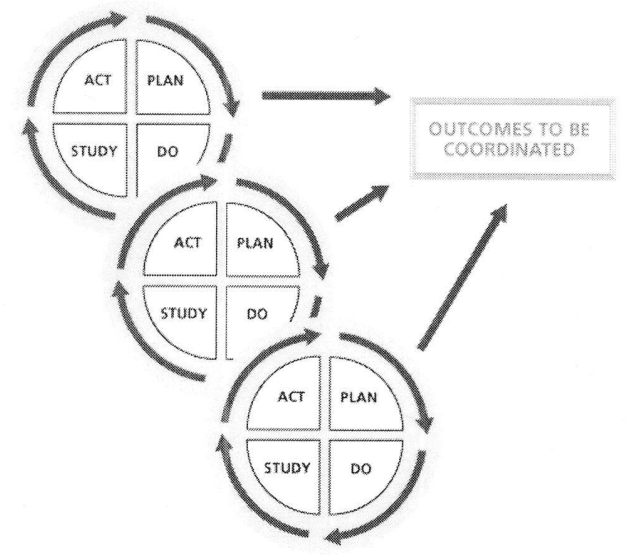

Figure 3. Coordinating Outcomes.

Figure 1 and 2: NHS Institute for Innovation and Improvement (2007). Plan Do Study Act (PDSA). Retrieved November 28, 2007 from doi: www.nodelaysachiever.hhs.uk/ 
Appendix F

PDSA Plan

\section{Newport Hospital, Therapeutic Hypothermia}

\section{Date: April 2011}

\section{Demographics}

- 129 Bed Hospital

- 18 Bed Emergency Department

- 10 Bed ICU

- 3 Intensivists

- Hospitalist Service

- 25 ICU Nurses

- 35 ER Nurses

\section{Plan:}

- Schedule a two hour lecture on Therapeutic Hypothermia for January 2011

- *Submit Therapeutic Hypothermia Lecture for RISNA Contact Hours

- *Develop support resources for the units: Family Education Brochure, Family Meeting Guide \& Therapeutic Hypothermia Resource Notebook

\section{Do:}

- *Continue "Just-In-Time" Education to ER and ICU nursing staff to reacquaint the staff with the policy

- *Offer lecture in July based on feedback from initial Therapeutic Hypothermia experience in ER and ICU

\section{Study (Beginning April 2011):}

- *Reassess the effectiveness of the "Just-In-Time" education when the first Therapeutic Hypothermia patients are treated

- *Assess further learning needs of the staff

- *Assess staff thoughts about the actual implementation of the policy

- *Encourage Feedback 
Appendix G

TH Program Flyer

Newport Hospital ED \& ICU Nurses

Lunch \& Learn

\section{Therapeutic Hypothermia in the ED and ICU}

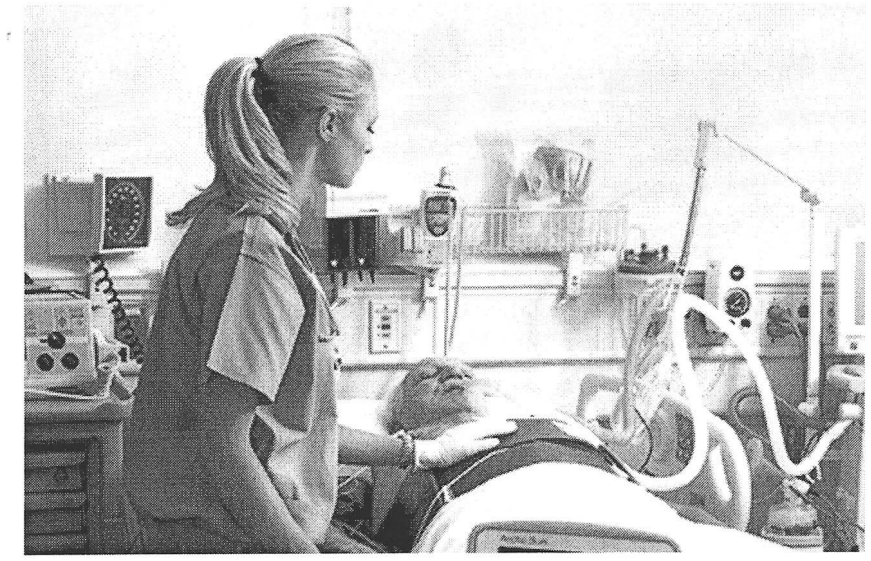

Laura Goldstein, RN, BS, CCRN, CMC Intensive Care Unit Northern Westchester Hospital \& CNS Graduate Nursing Student Masters Nursing Program Rhode Island College

January 10, 2012 12:30 - 1:30 PM

Newport Hospital

Gudoian Conference Room McLauren Building

Approved for 1.0 CEU by RISNA Email kbergeron@lifespan.org to register 


\section{Appendix $\mathrm{H}$}

\section{TH Educational Program Informational Letter}

RIH IRB Approval: 8/9/11

IRB Expiration: 8/8/12

Laura Goldstein

Senior Graduate Student

Rhode Island College

June , 2011

Therapeutic Hypothermia Educational Program Study Informational Letter

Dear Participant:

I am conducting a study of an educational program for Therapeutic Hypothermia to determine how much retention of educational content study participants will have after three months. I am recruiting subjects today to voluntarily participate in the study by completing a pre and post test today and agreeing to complete a post test in three (3) months.

To participate in this study you must circle a random number from 1-200 on the random numbers list. Choose a random letter other than your initial or birth date. Write your number, letter and your unit; Intensive Care Unit (ICU) or Emergency Department (ED), on the top of the pretest and post test papers. This is your identifier for the study. Place your completed papers in the sealed box at the end of class. Please retain your identifier. Your answers will be anonymous.

In three months I will distribute the same post test to all participants in the ICU and ED. No names will be used. You will be identified by your selected number, letter and unit. You will drop your completed three month post tests into a sealed box on the unit. Your responses will be put with your original pre and post tests for comparison.

While your Unit Director may have made attendance at the education program mandatory, your participation in the study is entirely voluntary. You are under no obligation to participate. All participants and subjects will receive CEU's for the class. There will be no compensation for participation. By writing a random number, letter and unit on your pre and post tests, you agree to participate in this study. Thank you for your help with this study. 


\section{Appendix I}

\section{TH Pre- and Post-Test}

Study Identifier

Unit

Date

\section{Mild Therapeutic Hypothermia}

Pretest

Instructions: Circle the best answer from the following multiple choice questions.

1. Mild Therapeutic Hypothermia is defined as a body temperature of :
a. $32^{\circ} \mathrm{C}-34^{\circ} \mathrm{C}$
b. $26^{\circ} \mathrm{C}-32^{\circ} \mathrm{C}$
c. $30^{\circ} \mathrm{C}-33^{\circ} \mathrm{C}$
d. $28^{\circ} \mathrm{C}-30^{\circ} \mathrm{C}$

2. Which one of the following is true for an unconscious patient following an out-of-hospital cardiac arrest?

a. Cerebral reperfusion may promote secondary injury to fluid shifts from the intracellular to the extracellular spaces increasing cerebral edema.

b. Cerebral reperfusion may benefit the patient secondary to increased oxygen free radicals available.

c. Cerebral reperfusion may promote injury secondary to an increased accumulation of oxygen free radicals and activation of degradive enzymes.

d. Cerebral reperfusion may benefit patients by increasing their level of consciousness.

3. Newport Hospital's inclusion criteria for Mild Therapeutic Hypothermia includes a patient who has had cardiac arrest with return of spontaneous circulation but remains unconscious and:
a. has a MAP $<65$ and a GCS of 10
b. has a MAP $>65$ and a GCS of $<8$
c. has a GCS of $<10$ and is a full code
d. has a GCS of $>8$ and rapidly improving neurologic function

4. Newport Hospital's exclusion criteria for Therapeutic Hypothermia includes patients with:
a. a MAP > 65 and a history of liver disease
b. an initial cardiac rhythm of VF or VT and a recent history of surgery within 14 days
c. an MAP $<65$ and septic
d. refractory arrhythmias and $>18$ years of age

5. Baseline tests and labs that should be ordered and drawn prior to beginning cooling include:
a. CT scan; EEG; Liver panel; Cardiac Enzymes, and electrolytes
b. 12 lead EKG; PT, INR ,PTT; Cardiac Enzymes; Chem 12 with lipase, and BNP
c. Chest $X$-ray, $A B G$, Cardiac Enzymes, $C B C D$, and electrolytes
d. EEG; $A B G ; B N P ; C B C D$, and Chem 6 
6. The incidence of seizures in patients after sudden cardiac arrest is:
a. $4-16 \%$
b. $5-25 \%$
c. $10-15 \%$
d. $8-16 \%$

7. Which statement is not true about shivering management in Therapeutic Hypothermia:
a. Busperone potentiates Demerol and Fentanyl
b. Neuromuscular blockers may decrease shivering.
c. Sedatives such as Fentanyl and Versed decrease shivering threshold as well as sedate.
d. Anesthetics such as Propofol and Pentobarbitol may decrease shivering threshold and sedate

8. Potential side effects of the Maintenance Phase of Therapeutic Hypothermia include all but:
a. Insulin resistance and pneumonia
b. Wound infection and hyperglycemia
c. Electrolyte imbalance and bradycardia
d. Tachycardia and skin breakdown

9. Rapid rewarming may lead to all but:
a. hypokalemia
b. increased intracranial pressure
c. hyperglycemia
d. sudden vasodilitation

\section{Symptoms of families in crisis include:}
1. Anxiety and depression
2. Inability to concentrate and insomnia
3. Nightmares and inability to cope
4. Uncertainty about outcome and acute and post traumatic stress disorder
a. 1 and 3
b. 2 and 4
c. 1 and 4
d. all of the above 
Answers:

1. a

2. c

3. b

4. $c$

5. b

6. b

7. c

8. d

9. a

10. d 


\title{
Appendix J
}

\section{RISNA Program Evaluation}

\section{RISNA Continuing Education Program Evaluation}

\section{Therapeutic Hypothermia in the ED and ICU}

\begin{abstract}
Each participant must complete an evaluation to receive a contact hour certificate for this educational activity. please be as honest and objective as possible.
\end{abstract}

1. Rate the extent to which the objectives were met by circling the appropriate number.

\begin{tabular}{|l|c|c|c|}
\hline $\begin{array}{l}\text { Learner's achievement of each objective } \\
\text { (list each objective below) }\end{array}$ & Met & Partially met & Not met \\
\hline 1.Define Therapeutic Hypothermia (TH) & 1 & 2 & 3 \\
\hline 2.Discuss landmark studies & 1 & 2 & 3 \\
\hline 3. Discuss post cardiac arrest syndrome & 1 & 2 & 3 \\
\hline 4. Discuss the neuroprotective effects of TH & 1 & 2 & 3 \\
\hline $\begin{array}{l}\text { 5. Identify current AHA guidelines \& } \\
\text { recommendations }\end{array}$ & 1 & 2 & 3 \\
\hline $\begin{array}{l}\text { 6.Discuss Newport Hospital's TH policy and } \\
\text { equipment }\end{array}$ & 1 & 2 & 3 \\
\hline $\begin{array}{l}\text { 7.Discuss potential complications, } \\
\text { pharmacological effects, and nursing care of } \\
\text { the TH patient }\end{array}$ & 1 & 2 & 3 \\
\hline 8.Discuss family centered care and TH & 1 & 2 & 3 \\
\hline
\end{tabular}

2. Rate the relevance of the objectives to overall purpose/goals.

\begin{tabular}{|l|c|c|c|}
\hline & $\begin{array}{c}\text { Yes } \\
\text { related }\end{array}$ & $\begin{array}{c}\text { Yes } \\
\text { Partially related }\end{array}$ & $\begin{array}{c}\text { No } \\
\text { Not related }\end{array}$ \\
\hline $\begin{array}{l}\text { Relevance of the objectives to overall purpose/goals } \\
\text { of the educational activity. }\end{array}$ & 1 & 2 & 3 \\
\hline
\end{tabular}

3. Rate the teaching expertise of the presenter.

\begin{tabular}{|l|c|c|c|}
\hline Laura Goldstein & & & \\
\hline $\begin{array}{l}\text { Evaluation of presenter (list each speaker followed } \\
\text { by the 2 ratings below) }\end{array}$ & Met & Partially met & Not met \\
\hline Speaker's expertise enhanced the activity. & 1 & 2 & 3 \\
\hline $\begin{array}{l}\text { Teaching strategies were appropriate for the } \\
\text { objectives and content. }\end{array}$ & 1 & 2 & 3 \\
\hline OR & & & \\
\hline Kathy Bergeron & & & Met \\
\hline $\begin{array}{l}\text { Evaluation of presenter (list each speaker followed } \\
\text { by the 2 ratings below) }\end{array}$ & Partially met & \\
\hline Speaker's expertise enhanced the activity. & 1 & 2 & 3 \\
\hline $\begin{array}{l}\text { Teaching strategies were appropriate for the } \\
\text { objectives and content. }\end{array}$ & 1 & 2 & 3 \\
\hline
\end{tabular}


4. Rate the appropriateness of physical facilities.

\begin{tabular}{|l|c|c|c|}
\hline & Appropriate & $\begin{array}{c}\text { Somewhat } \\
\text { appropriate }\end{array}$ & $\begin{array}{c}\text { Not } \\
\text { appropriate }\end{array}$ \\
\hline Appropriateness of physical facilities & 1 & 2 & 3 \\
\hline 5. Conflict of interest disclosure & & & \\
\hline Conflict of Interest disclosed & Met & Not met & NiA \\
\hline Comments: & 1 & 2 & 3 \\
\hline
\end{tabular}

Comments:

Recommendations for future programs: 
Appendix K

RISNA Contact Hours Certificate

\section{CERTIFICATE OF ATTENDANCE and SUCCESSFUL COMPLETION \\ Newport Hospital, Newport, Rhode Island \\ Applicant Name, Address, City and State}

Awards

Name of Participant

$1.0 \quad$ Contact Hours

Therapeutic Hypothermia in the ED and ICU

Title of Nursing Education Activity

January 10, 2012

Date

Newport Hospital, Newport, Rhode Island

Place, City and State

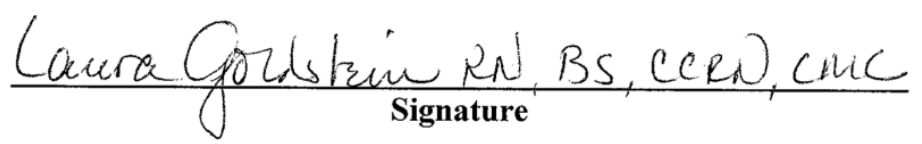

THIS CONTINUING NURSING EDUCATION ACTIVITY WAS APPROVED BY THE RHODE ISLAND STATE NURSES ASSOCIATION, AN ACCREDITED APPROVER BY THE AMERICAN NURSES CREDENTIALING CENTER'S COMMISSION ON ACCREDITATION 
Appendix L

ICU Nurses' Scores on Pre- and Post-Tests

\begin{tabular}{|c|c|c|}
\hline Question & $\begin{array}{l}\text { ICU Pre- } \\
\text { Test } \\
\text { Answers }\end{array}$ & $\begin{array}{l}\text { ICU } \\
\text { Post-test } \\
\text { Answers }\end{array}$ \\
\hline $\begin{array}{l}\text { 1. Mild Therapeutic Hypothermia is defined as a body tempera- } \\
\text { ture of : } \\
\text { a. } 32^{\circ} \mathrm{C}-34^{\circ} \mathrm{C} \text { (Correct Answer) } \\
\text { b. } 26^{\circ} \mathrm{C}-32^{\circ} \mathrm{C} \\
\text { c. } 30^{\circ} \mathrm{C}-33^{\circ} \mathrm{C} \\
\text { d. } 28^{\circ} \mathrm{C}-30^{\circ} \mathrm{C}\end{array}$ & $\begin{array}{lc}\text { a. } & 12 \\
\text { b. } & 0 \\
\text { c. } & 2 \\
\text { d. } & 0\end{array}$ & $\begin{array}{lc}\text { a. } & \mathbf{1 3} \\
\text { b. } & 0 \\
\text { c. } & 1 \\
\text { d. } & 0\end{array}$ \\
\hline $\begin{array}{l}\text { 2. Which one of the following is true for an unconscious patient } \\
\text { following an out-of-hospital cardiac arrest? } \\
\text { a. Cerebral reperfusion may promote secondary injury to } \\
\text { fluid shifts from the intracellular to the extracellular spaces } \\
\text { increasing cerebral edema. } \\
\text { b. Cerebral reperfusion may benefit the patient secondary to } \\
\text { increased oxygen free radicals available. } \\
\text { c. Cerebral reperfusion may promote injury secondary to an } \\
\text { increased accumulation of oxygen free radicals and } \\
\text { activation of degradive enzymes. (Correct Answer) } \\
\text { d. Cerebral reperfusion may benefit patients by increasing their } \\
\text { level of consciousness. }\end{array}$ & $\begin{array}{l}\text { a. } 3 \\
\text { b. } 3 \\
\text { c. } 2 \\
\text { d. } 5 \\
\text { No ans. } 1\end{array}$ & $\begin{array}{l}\text { a. } 1 \\
\text { b. } 2 \\
\text { c. } 7 \\
\text { d. } 4\end{array}$ \\
\hline $\begin{array}{l}\text { 3. Newport Hospital's inclusion criteria for Mild Therapeutic } \\
\text { Hypothermia includes a patient who has had cardiac arrest } \\
\text { with return of spontaneous circulation but remains uncon- } \\
\text { scious and: } \\
\text { a. has a MAP }<65 \text { and a GCS of } 10 \\
\text { b. has } \boldsymbol{a} M \boldsymbol{A P}>65 \text { and } \boldsymbol{a} \text { GCS of }<\boldsymbol{8} \text { (Correct } \text { Answer) } \\
\text { c. has a GCS of }<10 \text { and is a full code } \\
\text { d. has a GCS of }>8 \text { and rapidly improving neurologic function }\end{array}$ & $\begin{array}{ll}\text { a. } & 1 \\
\text { b. } & \mathbf{1 0} \\
\text { c. } & 2 \\
\text { d. } & 1\end{array}$ & $\begin{array}{ll}\text { a. } & 0 \\
\text { b. } & \mathbf{1 2} \\
\text { c. } & 0 \\
\text { d. } & 2\end{array}$ \\
\hline $\begin{array}{l}\text { 4. Newport Hospital's exclusion criteria for Therapeutic } \\
\text { Hypothermia includes patients with: } \\
\text { a. a MAP }>65 \text { and a history of liver disease } \\
\text { b. an initial cardiac rhythm of VF or VT and a recent history of } \\
\text { c. an } M A P<65 \text { and septic (Correct } \text { Answer) } \\
\text { d. refractory arrhythmias and }>18 \text { years of age }\end{array}$ & $\begin{array}{lc}\text { a. } & 1 \\
\text { b. } & 1 \\
\text { c. } & 12 \\
\text { d. } & 0\end{array}$ & $\begin{array}{l}\text { a. } 0 \\
\text { b. } 1 \\
\text { c. } \mathbf{1 3} \\
\text { d. } 0\end{array}$ \\
\hline $\begin{array}{l}\text { 5. Baseline tests and labs that should be ordered and drawn } \\
\text { prior to beginning cooling include: }\end{array}$ & & \\
\hline
\end{tabular}




\begin{tabular}{|c|c|c|}
\hline $\begin{array}{l}\text { a. } \mathrm{CT} \text { scan; EEG; Liver panel; Cardiac Enzymes, and electrolytes } \\
\text { b. } 12 \text { lead EKG; PT, INR,PTT; Cardiac Enzymes; Chem } \mathbf{1 2} \\
\text { with lipase, and BNP (Correct Answer) } \\
\text { c. Chest X-ray, ABG, Cardiac Enzymes, CBCD, and electrolytes } \\
\text { d. EEG; ABG; BNP; CBCD, and Chem } 6\end{array}$ & $\begin{array}{l}\text { a. } 3 \\
\text { b. } 8 \\
\text { c. } 3 \\
\text { d. } 0\end{array}$ & $\begin{array}{l}\text { a. } 2 \\
\text { b. } 9 \\
\text { c. } 3 \\
\text { d. } 0\end{array}$ \\
\hline $\begin{array}{l}\text { 6. The incidence of seizures in patients after sudden cardiac } \\
\text { arrest is: } \\
\text { a. } 4-16 \% \\
\text { b. } 5-25 \% \text { (Correct Answer) } \\
\text { c. } 10-\mathbf{1 5 \%} \\
\text { d. } 8-16 \%\end{array}$ & $\begin{array}{ll}\text { a. } & 1 \\
\text { b. } 6 \\
\text { c. } 7 \\
\text { d. } 0\end{array}$ & $\begin{array}{l}\text { a. } 1 \\
\text { b. } 9 \\
\text { c. } 4 \\
\text { d. } 0\end{array}$ \\
\hline $\begin{array}{l}\text { 7. Which statement is not true about shivering management in } \\
\text { Therapeutic Hypothermia: } \\
\text { a. Busperone potentiates Demerol and Fentanyl } \\
\text { b. Neuromuscular blockers may decrease shivering. } \\
\text { c. Sedatives such as Fentanyl and Versed decrease shivering } \\
\text { threshold as well as sedate. (Correct Answer) } \\
\text { d. Anesthetics such as Propofol and Pentobarbitol may decrease } \\
\text { shivering threshold and sedate. }\end{array}$ & $\begin{array}{l}\text { a. } 0 \\
\text { b. } 7 \\
\text { c. } 4 \\
\text { d. } 3\end{array}$ & $\begin{array}{l}\text { a. } 0 \\
\text { b. } 2 \\
\text { c. } 9 \\
\text { d. } 3\end{array}$ \\
\hline $\begin{array}{l}\text { 8. Potential side effects of the Maintenance Phase of } \\
\text { Therapeutic Hypothermia include all but: } \\
\text { a. Insulin resistance and pneumonia } \\
\text { b. Wound infection and hyperglycemia } \\
\text { c. Electrolyte imbalance and bradycardia } \\
\text { d. Tachycardia and skin breakdown (Correct Answer) }\end{array}$ & $\begin{array}{l}\text { a. } 3 \\
\text { b. } 1 \\
\text { c. } 5 \\
\text { d. } 5\end{array}$ & $\begin{array}{ll}\text { a. } & 0 \\
\text { b. } & 2 \\
\text { c. } & 2 \\
\text { d. } & \mathbf{1 0}\end{array}$ \\
\hline $\begin{array}{l}\text { 9. Rapid rewarming may lead to all but: } \\
\text { a. Hypokalemia (Correct Answer) } \\
\text { b. Increased intracranial pressure } \\
\text { c. Hyperglycemia } \\
\text { d. Sudden vasodilitation }\end{array}$ & $\begin{array}{l}\text { a. } 6 \\
\text { b. } 5 \\
\text { c. } 3 \\
\text { d. } 0\end{array}$ & $\begin{array}{ll}\text { a. } & \mathbf{1 0} \\
\text { b. } 1 \\
\text { c. } 2 \\
\text { d. } 1\end{array}$ \\
\hline $\begin{array}{l}\text { 10. Symptoms of families in crisis include: } \\
\text { 1. Anxiety and depression } \\
\text { 2. Inability to concentrate and insomnia } \\
\text { 3. Nightmares and inability to cope } \\
\text { 4. Uncertainty about outcome and acute and post- traumatic } \\
\text { stress disorder } \\
\text { Choose one: } \\
\text { a. } 1 \text { and } 3 \\
\text { b. } 2 \text { and } 4 \\
\text { c. } 1 \text { and } 4 \\
\text { d. all of the above (Correct Answer) }\end{array}$ & $\begin{array}{l}\text { a. } 0 \\
\text { b. } 0 \\
\text { c. } 1 \\
\text { d. } 12 \\
\text { No Ans. } 1\end{array}$ & $\begin{array}{l}\text { a. } 0 \\
\text { b. } 0 \\
\text { c. } 0 \\
\text { d. } 13 \\
\text { No Ans. } 1\end{array}$ \\
\hline
\end{tabular}


Appendix M

ED Nurse Scores on Pre- and Post-Tests.

\begin{tabular}{|c|c|c|}
\hline Question & $\begin{array}{l}\text { ED } \\
\text { Pretest } \\
\text { Answers }\end{array}$ & $\begin{array}{l}\text { ED } \\
\text { Post test } \\
\text { Answers }\end{array}$ \\
\hline $\begin{array}{l}\text { 1. Mild Therapeutic Hypothermia is defined as a body tempera- } \\
\text { ture of : } \\
\text { a. } 32^{\circ} \mathrm{C}-34^{\circ} \mathrm{C} \text { (Correct Answer) } \\
\text { b. } 26^{\circ} \mathrm{C}-32^{\circ} \mathrm{C} \\
\text { c. } 30^{\circ} \mathrm{C}-33^{\circ} \mathrm{C} \\
\text { d. } 28^{\circ} \mathrm{C}-30^{\circ} \mathrm{C}\end{array}$ & $\begin{array}{ll}\text { a. } & 6 \\
\text { b. } & 1 \\
\text { c. } & 1 \\
\text { d. } & 2\end{array}$ & $\begin{array}{ll}\text { a. } & \mathbf{1 0} \\
\text { b. } & 0 \\
\text { c. } & 0 \\
\text { d. } & 0\end{array}$ \\
\hline $\begin{array}{l}\text { 2. Which one of the following is true for an unconscious patient } \\
\text { following an out-of-hospital cardiac arrest? } \\
\text { a. Cerebral reperfusion may promote secondary injury to } \\
\text { fluid shifts from the intracellular to the extracellular spaces } \\
\text { increasing cerebral edema. } \\
\text { b. Cerebral reperfusion may benefit the patient secondary to } \\
\text { increased oxygen free radicals available. } \\
\text { c. Cerebral reperfusion may promote injury secondary to an } \\
\text { increased accumulation of oxygen free radicals and } \\
\text { activation of degradive enzymes. (Correct Answer) } \\
\text { d. Cerebral reperfusion may benefit patients by increasing their } \\
\text { level of consciousness. }\end{array}$ & $\begin{array}{l}\text { a. } 2 \\
\text { b. } 4 \\
\text { c. } 0 \\
\text { d. } 4\end{array}$ & $\begin{array}{l}\text { a. } 2 \\
\text { b. } 3 \\
\text { c. } 4\end{array}$ \\
\hline $\begin{array}{l}\text { 3. Newport Hospital's inclusion criteria for Mild Therapeutic } \\
\text { Hypothermia includes a patient who has had cardiac arrest } \\
\text { with return of spontaneous circulation but remains uncon- } \\
\text { scious and: } \\
\text { a. has a MAP }<65 \text { and a GCS of } 10 \\
\boldsymbol{b} \text {. has } \boldsymbol{a} \boldsymbol{M A P}>\mathbf{6 5} \text { and } \boldsymbol{a} \boldsymbol{G C S} \text { of }<\boldsymbol{8} \text { (Correct Answer) } \\
\text { c. has a GCS of }<10 \text { and is a full code } \\
\text { d. has a GCS of }>8 \text { and rapidly improving neurologic function }\end{array}$ & $\begin{array}{l}\text { a. } 2 \\
\text { b. } 5 \\
\text { c. } 2 \\
\text { d. } 0 \\
\text { No ans. } 1\end{array}$ & $\begin{array}{ll}\text { a. } & 1 \\
\text { b. } & 9 \\
\text { c. } & 0 \\
\text { d. } & 0\end{array}$ \\
\hline
\end{tabular}




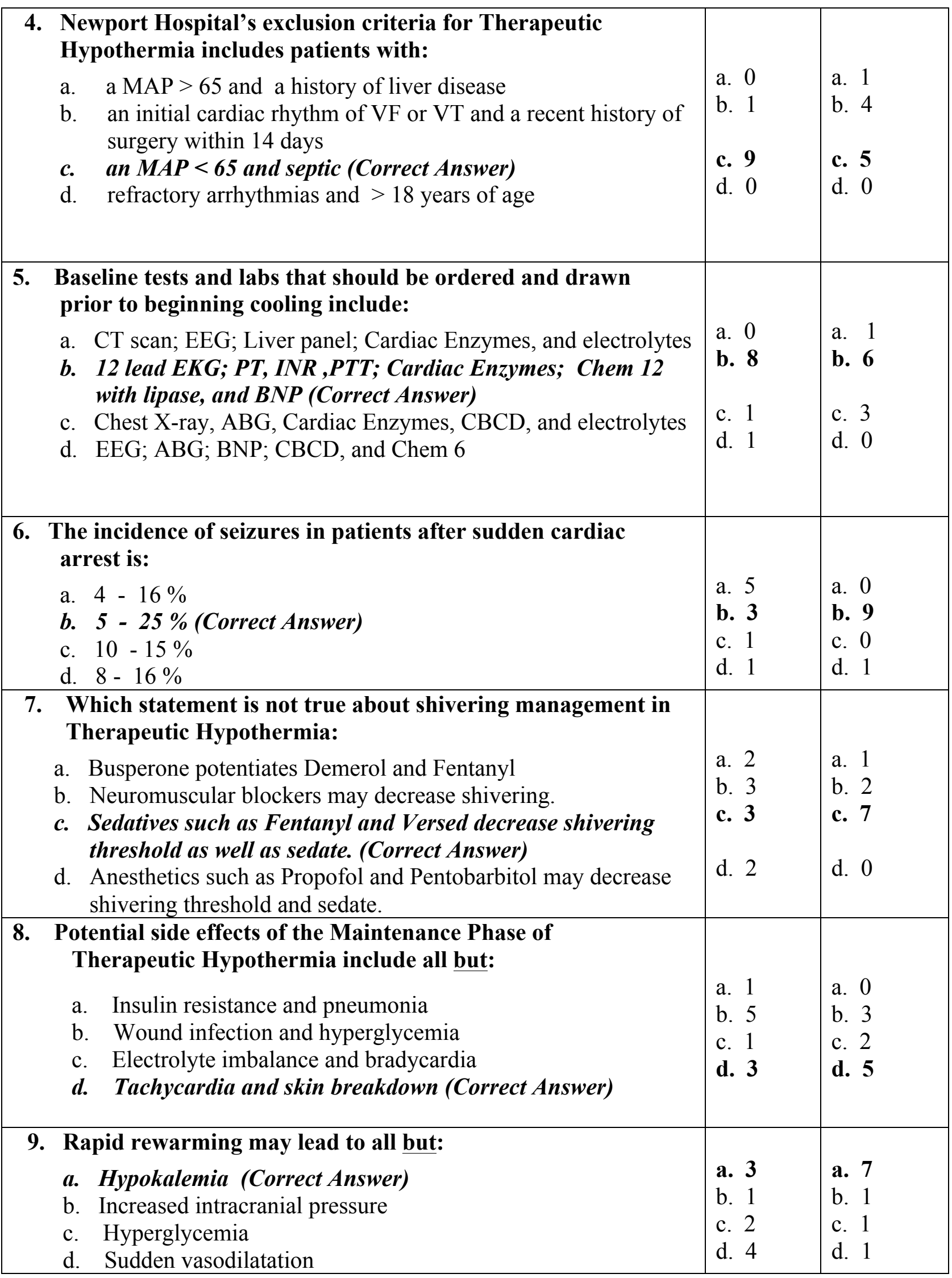




\begin{tabular}{|l|l|l|}
\hline 10. Symptoms of families in crisis include: & a. 0 & a. 0 \\
1. Anxiety and depression & b. 0 & b. 0 \\
2. Inability to concentrate and insomnia & c. 1 & c. 0 \\
3. Nightmares and inability to cope & d. 9 & d. $\mathbf{1 0}$ \\
4. Uncertainty about outcome and acute and post-traumatic & & \\
stress disorder & & \\
Choose one: & \\
a. 1 and 3 & & \\
b. 2 and 4 & & \\
c. 1 and 4 & & \\
d. all of the above (Correct Answer) &
\end{tabular}

